\title{
Worldwide wavelet analysis of geomagnetic jerks
}

\author{
Mioara Alexandrescu, ${ }^{1}$ Dominique Gibert,${ }^{2}$ Gauthier Hulot, ${ }^{1}$ \\ Jean-Louis Le Mouël, ${ }^{1}$ and Ginette Saracco ${ }^{2}$
}

\begin{abstract}
Following an earlier study which gives the principles of the method and an example of application to the eastern component of the magnetic field in the European region [Alexandrescu et al., 1995], detection and characterization of geomagnetic jerks using wavelet analysis is generalized to any horizontal component of the field and to a worldwide distribution (involving 97 locations) of observations. This allows for a systematic and global search for such events within the twentieth century and makes it possible to unravel a number of intriguing properties associated with them. Whereas our first study only reveals five such events in Europe, we can now state that seven and only seven events have apparently occurred throughout the world during the present century. Two (1969 and 1978) are unquestionably of global extent, three $(1901,1913$, and 1925) being possibly of similar extent, while the remaining two (1932 and 1949) are not seen everywhere at the Earth's surface. We confirm our early result that the events are more singular than previously thought, with a "regularity" systematically closer to 1.5 than to 2 , and a common mean value of about 1.6. Furthermore, the 1969 and 1978 events display a two-step spatio-temporal behavior consisting of an "early arrival" in the northern hemisphere, a "late arrival" in the southern hemisphere, and a time lag between the two arrivals of the order of a couple of years. We were also able to show that the 1969 and 1978 events tend to at least partially balance each other. The extent to which this is true remains to be assessed, mainly because our method, although already providing some information about the geometry of the events, does not yet allow the proper recovery of their intensities.
\end{abstract}

\section{Introduction}

Assessing the exact nature of the time changes of the magnetic field of internal origin at the surface of the Earth and at the core-mantle boundary is important, not only for its own sake but also for the information it can give about the deep Earth, such as the electrical conductivity of the lower mantle, the motions at the surface the fluid core, and the interaction between the core and the mantle.

The identification of an abrupt change in the trend of the geomagnetic secular variation, referred to as a "jerk" [Courtillot et al., 1978; Malın et al., 1983], and the demonstration that it really is of internal origin, required quite some efforts in the past years. This internal origin now seems to be well established. Malin and Hodder [1982] devised a filter to measure the magnitude of the 1970 discontinuity in the second time derivative

\footnotetext{
'Institut de Physique du Globe de Paris, Paris, France.

${ }^{2}$ Géosciences Rennes - Centre National de la Recherche

Scientifique/Institut National des Sciences de l'Univers, Rennes, France.

Copyright 1996 by the American Geophysical Union.

Paper number 96JB01648.

0148-0227/96/96JB-01648\$09.00
}

of the field components at 83 observatories; performing a spherical harmonic analysis of these magnitudes led them to conclude that most of the sudden change is indeed of internal origin. Gubbins and Tomlinson [1986] removed the external field effects from the data and attributed the discontinuity in the time derivatives of the resulting time series to an internal origin. Gavoret et al. [1986] analyzed monthly mean values and also stressed the internal nature of the phenomenon.

However, the definition and characteristics of the geomagnetic jerks are still a matter of debate in the geomagnetic community. Even the fundamental parameters of a jerk, such as the date at which it occurs, the time duration of the impulse, or the worldwide character of the event are not agreed upon by all the researchers.

The late 1960 s event has for instance been reported as occurring in 1969 [Courtillot et al., 1978; Courtillot and Le Mouël, 1984; McLeod, 1985, 1989; Golovkov et al., 1989], 1970 [Stewart and Whaler, 1995], or 1971/1972 in the Australian region [Gubbins and Tomlinson, 1986; Whaler, 1987]. Another sudden change in the secular acceleration of the geomagnetic field has been reported around 1978 [Gavoret et al., 1986; Gubbins and Tomlinson, 1986; Langel et al., 1986; McLeod, 1989; Stewart and Whaler, 1995]. Stewart [1991] indicated the existence of another jerk in 1983, also detected in South 
Africa by Kotzé et al. [1991] and on South Georgia island by Dowson et al. [1988]. Other jerks have also been detected earlier in this century: in 1913 [Courtillot and Le Mouël, 1984; Ducruix and Le Mouël, 1983; Gire et al., 1984] and in 1925 [McLeod, 1989], and a number of suggestions have been made for some jerks in 1940 [McLeod, 1989], 1937, 1947, and 1958 [Golovkov et al., 1989]. However, in a recent study focusing on the European area and using the wavelet analysis of monthly mean values, five and only five events have been detected since the beginning of this century: around 1902, 1913, 1925, 1969, and 1978 [Alexandrescu et al., 1995]. As this method has been proved to be objective and efficient, we now present a systematic and worldwide analysis in order to exactly assess the existence, timing (and possible regional delays), and general characteristics of such events.

A good determination of the duration (which can be defined as the time needed for the change of slope in the time series of the secular variation to be completed), and time of occurrence of these events is very much required. A change of the core field in a time span of about a year or less would, for instance, shorten the period of variations of internal origin as given by early estimates [Currie, 1967, 1968; Alldredge, 1984]. Also, the effect of the conducting mantle could be addressed with better data. Backus [1983], who discussed the filtering effect of the mantle and suggested that it behaves as a causal time-invariant real linear filter, noted that the centroid date (emergence time) and smoothing time of the jerk could be different at different locations at the Earth surface, even in the case of an ideal jerk occurring at the core-mantle boundary. A study of the jerks using a time sampling which could resolve these differences would therefore prove very valuable.

Up to now most studies focused on the European region [Ducruix et al., 1980; Achache et al., 1980; Gavoret et al., 1986] which has by far the best coverage of observatories and for which the impulse field usually has a strong $Y$ (east) component. But impulses are also known to be found in other components and elsewhere [see Courtillot and Le Mouel, 1988]. Analyzing only the usual orthogonal components of the geomagnetic field $(X, Y, Z)$ may mean that impulses might have been masked at some places due to this choice of axes. In the present study we will therefore extend our previous analysis [Alexandrescu et al., 1995] (hereinafter referred to as paper 1) to worldwide data and apply the wavelet analysis to linear combinations of the horizontal components $(X$ and $Y$ ), in order to better estimate the characteristics of the jerks.

\section{Method of Analysis}

\section{Detection of Singularities With Wavelets}

The theoretical background is identical to the one described in paper 1, except for a few details, and the reader is referred to this paper for a full description of wavelet analysis applied to singularity detection. A brief description of the main aspects of the method is given in the appendix. A significant difference with our previous study is that the present analysis is no longer restricted to the $Y$ component. It is generalizer' and aims at recovering the direction and sense of the horizontal component of the jerk.

Now, as in paper 1, we will assume that the signal recorded in the observatories is the sum of a main-field signal containing singularities, that is, jerks, an external long-period signal, and noise. In paper 1 we decomposed the analyzed $Y$ component in the following canonical form:

$$
Y(t)=\beta j_{\alpha}(t)+h_{Y}(t)+n_{Y}(t),
$$

where $\beta j_{\alpha}$ is the jerk signal (it represents an abrupt change with a regularity $\alpha$ and intensity $\beta$ localized at the time $t_{0}$ ):

$$
j_{\alpha}(t)=\left\{\begin{array}{ll}
0 & t \leq t_{\circ} \\
\left(t-t_{0}\right)^{\alpha} & t>t_{\circ}
\end{array},\right.
$$

$h_{Y}$ is the $Y$ component of the "periodic" external signal and $n_{Y}$ the noise on the $Y$ component. Let us now generalize this decomposition to the horizontal component $\vec{H}(t)$ of the field. The external signal $\vec{h}$ can reasonably be supposed to be linearly polarized, as it is mainly generated by the ring current. We will also assume that the jerk signal is linearly polarized. This means that the jerk components $X$ and $Y$ are assumed to be proportional and to share the same regularity. This is a strong assumption we might need to reconsider later on. But it will allow us to detect the direction along which the jerk is the strongest. We will then be able to determine its characteristics along this particular direction.

We will therefore assume that

$$
\begin{aligned}
& X(t)=\beta \cos (\theta) j_{\alpha}(t)+\cos (\varphi) h(t)+n_{X}(t), \\
& Y(t)=\beta \sin (\theta) j_{\alpha}(t)+\sin (\varphi) h(t)+n_{Y}(t) .
\end{aligned}
$$

The noise will be considered as being isotropic. The angle $\theta$ (counted eastward from the geographical north direction) will be called the direction angle of the jerk; $\varphi$ the direction angle of the external signal.

The first step of the analysis consists in computing a set of linear combinations of the original components:

$$
f_{\theta^{\prime}}(t)=\cos \left(\theta^{\prime}\right) X(t)+\sin \left(\theta^{\prime}\right) Y(t),
$$

where the rotation angle $\theta^{\prime}$ spans $[0, \pi]$. The second step consists of taking the wavelet transform of the signal (see the appendix). The linearity of the wavelet transform implies that

$$
\begin{aligned}
W f_{\theta^{\prime}}(t, a) & =\cos \left(\theta^{\prime}\right) W X(t, a)+\sin \left(\theta^{\prime}\right) W Y(t, a) \\
& =\beta \cos \left(\theta-\theta^{\prime}\right) W j_{\alpha}(t, a) \\
& +\cos \left(\varphi-\theta^{\prime}\right) W h(t, a) \\
& +W\left[n_{X} \cos \left(\theta^{\prime}\right)+n_{Y} \sin \left(\theta^{\prime}\right)\right](t, a) .
\end{aligned}
$$

For a rotation angle $\theta^{\prime}=\theta_{e}=\theta+\pi / 2$, the jerk is removed from the composite signal, and the wavelet trans- 
form of the rotated signal $f_{\theta_{e}}(t)$ is limited to the one of both the harmonic signals and the noise:

$$
\begin{aligned}
W f_{\theta_{e}}(t, a) & =\cos \left(\varphi-\theta_{e}\right) W h(t, a) \\
+W & {\left[n_{X} \sin \left(\theta_{e}\right)+n_{Y} \cos \left(\theta_{e}\right)\right](t, a) . }
\end{aligned}
$$

In this case, and in view of the results obtained in paper 1 , all ridge functions extracted from the wavelet transform $W f_{\theta_{e}}(t, a)$ should be either of type 2 (i.e., typical of the harmonic signals) or of type 3 (i.e., strongly altered by the random noise); see the appendix.

If the rotation angle is now $\theta^{\prime}=\theta_{b}=\varphi+\pi / 2$,
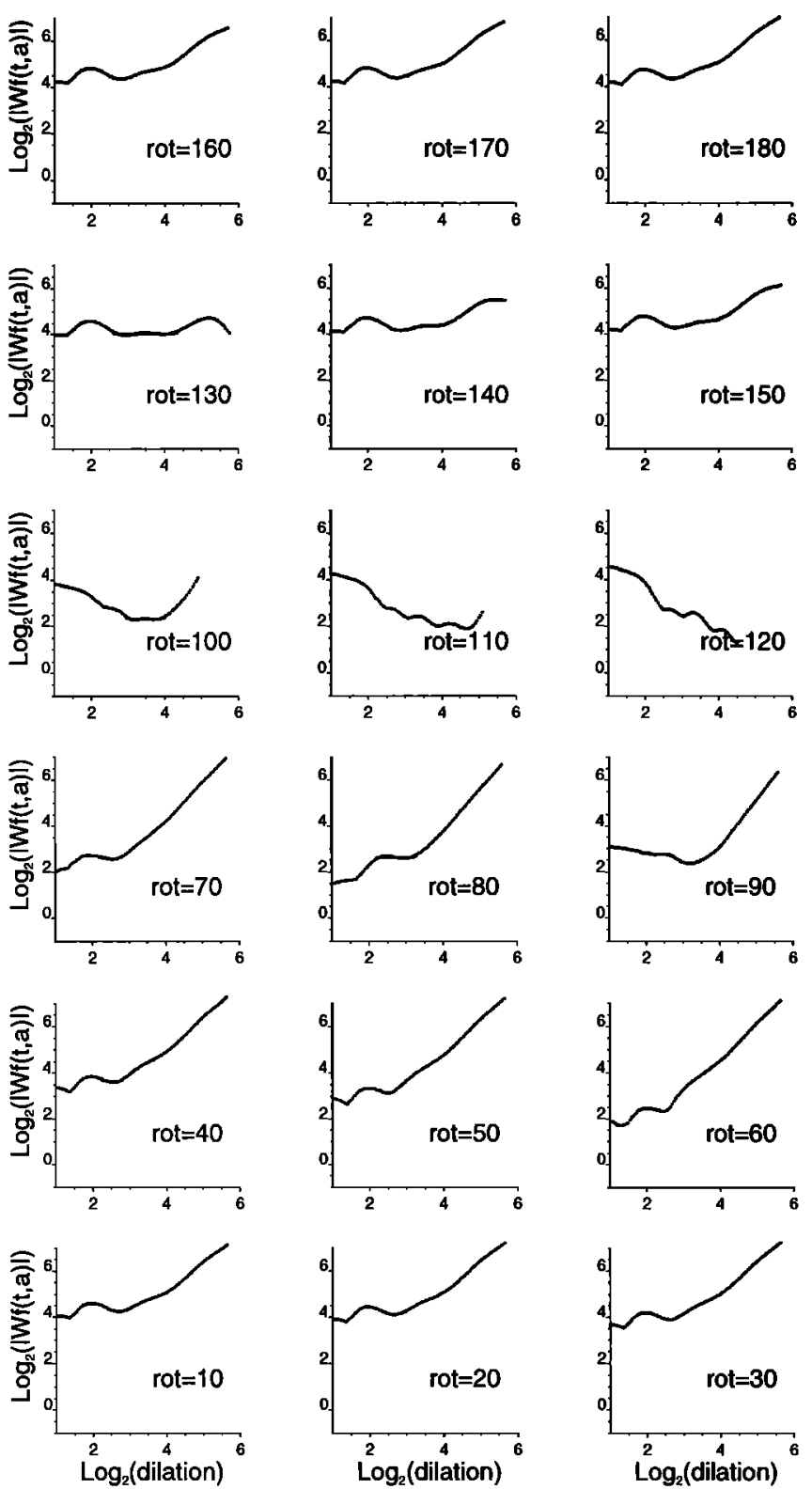

Figure 1. Ridge functions for the 1947 artificial jerk injected in the CLF series and computed for $\theta^{\prime}$ spanning $\left[0^{\circ}, 180^{\circ}\right]$ in steps of $10^{\circ}$. The ridge functions of type 2 observed for $\theta^{\prime}=130^{\circ}$ and $140^{\circ}$ correspond to the extinction of the jerk (as detected in Plate 1). Good quality ridge functions of type 1 are observed for $40^{\circ} \leq$ $\theta^{\prime} \leq 90^{\circ}$.

$$
\begin{aligned}
& W f_{\theta_{b}}(t, a)=\beta \cos \left(\theta-\theta_{b}\right) W j_{\alpha}(t, a) \\
&+W\left[n_{X} \cos \left(\theta_{b}\right)+n_{Y} \sin \left(\theta_{b}\right)\right](t, a),
\end{aligned}
$$

the contribution of the wavelet transform of the harmonic signal disappears and the ridge functions of type 1 associated with the jerk should be better detected in the wavelet transform $W f_{\theta_{b}}(t, a)$.

\section{Assessment of the Method}

We now give several synthetic examples to illustrate the theoretical considerations developed in the preceding section. As already mentioned, the results presented in this study have been obtained with the same analyzing wavelet as in paper 1 . However, in order to obtain the most reliable assessment of the method, we did not use the harmonic signal and synthetic noise described in this previous paper. Instead we used data extracted directly from six European observatories (BFE, CLF, ESK, HAD, LER, NGK) and covering the 1925-1970 period displaying no jerk (in Europe). To these time series, considered to be typical real signals free of any jerks, was superimposed a synthetic jerk with a regularity $\alpha=1.65$ and a strength $\beta=0.17 \mathrm{nT} \times$ month $^{-\alpha}$ estimated from the 1969 jerk detected in the Chambonla-Forêt $Y$ series (see equation (12) of paper 1).

We set $\theta=\pi / 4$, and the synthetic jerk was successively injected at $1943,1945,1947,1949$, and 1951 in order to look for some possible influence of the relative phasing of the external signal with respect to the jerk. From the previous section we can expect that both the date and the regularity of the jerk should be best estimated for $\theta^{\prime}=\theta_{b}=\varphi+\pi / 2$, and the jerk removed for $\theta^{\prime}=\theta_{e}=\theta+\pi / 2$. This was checked very efficiently using the movie procedure included in the seismic processing package distributed by the Center for Wave Phenomena at the Colorado School of Mines [Scales, 1995]. This is the way we determine the direction $\theta$ of the jerk. The sign of the jerk along this direction can then be recovered by inspection of the sign of the wavelet transform (see the appendix). In this way we finally get local characteristic directions for the jerk.

An example of a movie sequence represented at $10^{\circ}$ intervals for the CLF series and the 1947 synthetic jerk is shown on Plate 1. Such sequences have actually been computed for $5^{\circ}$ increments (not shown on Plate 1 for reasons of space) in order to accurately detect the extinction of the jerk which is clearly achieved within a limited range $\left(10^{\circ}\right)$ of angles $\theta^{\prime}$ around $\theta+\pi / 2$. The signature of the jerk is visible for a wide range of angles $\theta^{\prime}$ centered on $\theta_{b}$ in the form of a conelike patch of large amplitude. A precise determination of both the date and the regularity $\alpha$ of the event can be obtained from the ridge functions displaying the best type 1 behavior (Figure 1, which displays the 18 ridge functions corresponding to the sequence shown in Plate 1).

Since the appearance of the jerk is not as sudden as its extinction, type 1 ridge functions can be observed within an interval of $\theta^{\prime}$ of some tens of degrees. The center of this interval depends on both $\theta$ and $\varphi$, and 

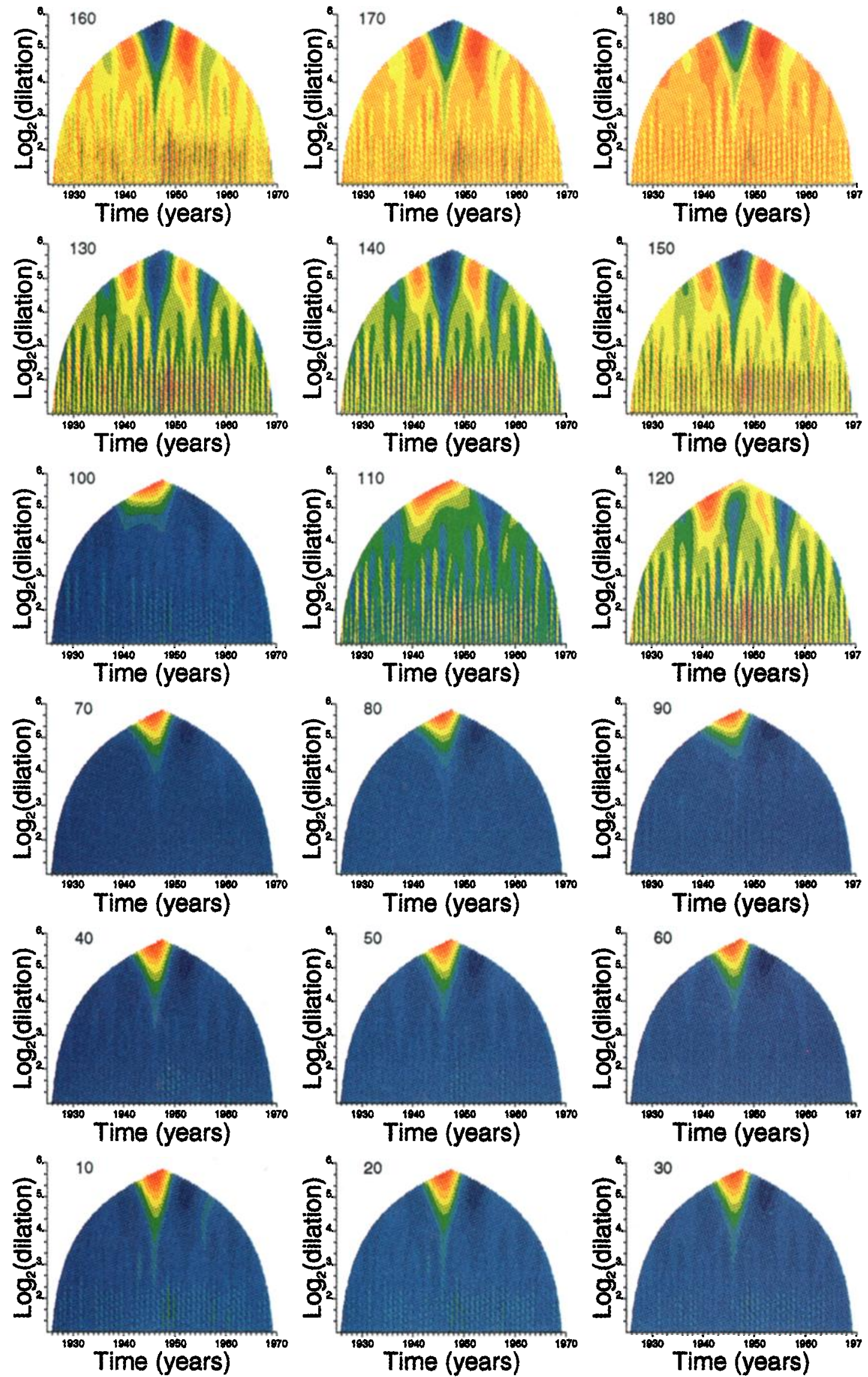
Table 1. Results of the Synthetic Tests

\begin{tabular}{lccccc}
\hline Date & Data & $\theta_{b}$, deg & Date & $\alpha$ & $\theta$, deg \\
\hline 1943.0 & 18 & $77(9)$ & $1942.6(0.2)$ & $1.62(0.10)$ & $47.5(2.5)$ \\
1945.0 & 18 & $70(8)$ & $1944.8(0.4)$ & $1.75(0.15)$ & $47.5(2.5)$ \\
1947.0 & 18 & $65(10)$ & $1946.4(0.3)$ & $1.65(0.13)$ & $46.1(3.1)$ \\
1949.0 & 18 & $70(8)$ & $1948.8(0.2)$ & $1.58(0.10)$ & $44.2(3.2)$ \\
1951.0 & 18 & $70(10)$ & $1950.3(0.5)$ & $1.70(0.14)$ & $44.4(3.0)$ \\
\hline
\end{tabular}

Numbers in parentheses are standard deviations.

gives a poor estimate of $\theta_{b}$ (to determine $\theta_{b}$ more accurately, we would symmetrically look for the direction $\varphi+\pi / 2$ which extinguishes the harmonic type ridge function).

Now, for the six previously mentioned synthetic series, we retrieved the extinction angle $\theta_{e}$ and examined the best type 1 ridge functions. The statistics of the results for the five injection dates are summarized in Table 1. These statistics include the three best type 1 ridge functions for each observatory. It appears that the method allows the recovery of the regularity $\alpha$ with a relative uncertainty of about $10 \%$ and the extinction angle $\theta_{e}$ within an error of the order of $5^{\circ}$. The dating of the jerks should ideally be done using the lines of extrema for very small dilations where the time localization of the wavelets is more precise (see the appendix). In practice, we use the smallest dilations unaffected by the noise and corresponding to the small-dilation end of the linear part of the ridge functions (i.e., $a \simeq 2^{3.5}$ as can be seen in Figure 1). The whole set of lines of extrema corresponding to the analyzed ridge functions of type 1 (Table 1) is shown on Figure 2. At small dilations $\left(a \leq 2^{35}\right)$, the lines are controlled by the noise and are scattered. For the dilation range corresponding to the linear part of the ridge functions $\left(a 2^{3.5}\right)$, the lines characterizing each date of artificial jerk are well localized within a time interval smaller than 1 year. However, this part of the lines of extrema form curved arches with their large-dilation end located at dates about 2 years before the theoretical dates. The statistics show that the dates obtained for the smallest dilation available (i.e., $a \simeq 2^{3.5}$ ) fall within an interval of about 6 months and that, due to the curvature of the lines of extrema, the average dates obtained are slightly biased (less than 6 months) toward the inferior dates (Table 1). Therefore in what follows, dilations $a \simeq 2^{35}$ will be used for dating the real jerks.

\section{Data Selection}

The present study has been performed on observatory monthly means (defined as being the average over all days of the month and all times of the day) obtained from the National Geophysical Data Center (NGDC, Boulder, Colorado) or directly from the observatories. In the latter case the data were either obtained in digital form or digitized from year books. For the purposes of the present study the first criterion in data selection was the length and continuity of the time series of the northward $(X)$ and eastward $(Y)$ components (available or computable from declination $(D)$ and horizontal intensity $(H))$. Only observatories for which time series were available over a continuous time interval longer than 12 years have been selected. We had to accept some gaps in some of the series and, in these cases, a linear interpolation was used to reconstruct the missing values; the largest gaps we corrected for were 6 months long. In the case of a longer gap the time series was split into two.

Following this initial selection, all time series were subjected to a careful validation procedure using the wavelet transform as in paper 1 . When anomalies were

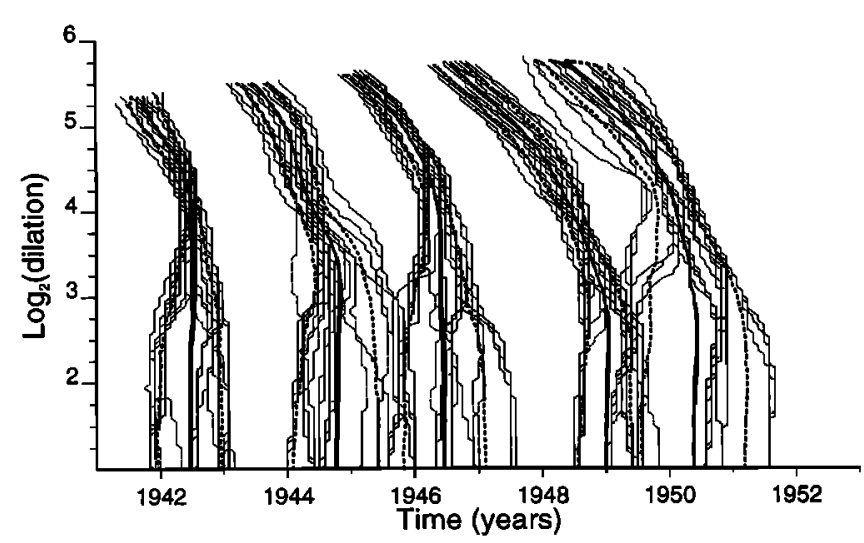

Figure 2. Lines of extrema extracted from the wavelet transforms computed from the five artificial jerks injected at 1943, 1945, 1947, 1949, and 1951 into the BFE, CLF, ESK, HAD, LER, and NGK data series. Only the best three lines are drawn (see text for details). For each artificial jerk the average of the lines of extrema (solid lines) indicates the time of occurrence (see also Table 1). Also shown are the standard deviations of the lines of extrema (dashed curves).

Plate 1. Wavelet transforms of the 1947 artificial jerk injected in the CLF series and computed for $\theta^{\prime}$ spanning $\left[0^{\circ}, 180^{\circ}\right]$ in steps of $10^{\circ}$. The extinction of the jerk begins for $\theta^{\prime}=100^{\circ}$ and it is complete for $\theta^{\prime}=130^{\circ}$. The color scale represents the sign of the wavelet transform: red indicates positive, blue indicates negative. 
Table 2a. Observatories Considered in the Present Study

\begin{tabular}{|c|c|c|c|c|c|c|}
\hline Code $^{a}$ & Name & $\lambda^{b}$ & $\varphi^{c}$ & Period $^{d}$ & Source $^{e}$ & Jump $^{f}$ \\
\hline $\mathrm{AAE}$ & Addis Abeba & 9.030 & 38.765 & 1958-1974 & obs & $\cdots$ \\
\hline $\mathrm{ABG}$ & Alibag & 18.638 & 76.917 & 1921-1991 & obs & $\ldots$ \\
\hline$A G N$ & Agincourt & 43.783 & 280.733 & $1932-1969$ & wdc & 1958 \\
\hline AIA & Faraday Islands & -65.245 & 295.742 & $1957-1984$ & obs & $\ldots$ \\
\hline AML & Amberley & -43.152 & 172.722 & $1923-1978$ & obs & $\cdots$ \\
\hline AMS & Martin de Vivies & -37.833 & 77.567 & 1981-1991 & bcmt & $\ldots$ \\
\hline AMT & Amatsia & 31.550 & 34.917 & $1976-1988$ & obs & $\ldots$ \\
\hline ANN & Annamalainagar & 11.367 & 79.683 & 1958-1991 & obs & $\cdots$ \\
\hline API & Apia & -13.807 & 188.225 & 1921-1989 & obs & $\cdots$ \\
\hline AQL & L'Aquila & 42.383 & 13.317 & $1960-1993$ & obs & $\cdots$ \\
\hline ARC & Arctowski & -62.160 & 301.522 & $1978-1993$ & obs & $\ldots$ \\
\hline ARS & Arti & 56.433 & 58.567 & $1945-1956$ & obs & $\cdots$ \\
\hline$\cdots$ & & $\cdots$ & $\cdots$ & $1973-1993$ & . & $\cdots$ \\
\hline BEL & Belsk & 51.837 & 20.792 & 1966-1994 & obs & $\ldots$ \\
\hline $\mathrm{BFE}$ & Brorfelde & 55.625 & 11.672 & $1907-1994$ & obs & 1982 \\
\hline BLC & Baker Lake & 64.333 & 263.967 & $1960-1994$ & wdc & $1969,1975,1977$ \\
\hline BNG & Bangui & 4.437 & 18.565 & 1955-1991 & bcmt & 1957 \\
\hline BOU & Boulder & 40.138 & 254.762 & $1967-1985$ & wdc & $\ldots$ \\
\hline BRW & Barrow & 71.323 & 203.380 & $1965-1989$ & wdc & $\ldots$ \\
\hline $\mathrm{CBB}$ & Cambridge Bay & 69.200 & 255.000 & $1973-1985$ & $\cdots$ & $\ldots$ \\
\hline CLF & Chambon la Forêt & 48.023 & 2.260 & $1883-1994$ & obs & $1957,1968,1983$ \\
\hline $\mathrm{CMO}$ & College & 64.860 & 212.163 & $1948-1982$ & wdc & 1947 \\
\hline $\mathrm{COI}$ & Coimbra & 40.222 & 351.378 & $1866-1942$ & obs & $\ldots$ \\
\hline$\cdots$ & & $\ldots$ & $\ldots$ & $1952-1992$ & obs & $\cdots$ \\
\hline $\mathrm{CZT}$ & Port Alfred & -46.433 & 51.867 & 1974-1991 & bcmt & $\ldots$ \\
\hline DBN & De Bilt & 52.102 & 5.177 & $1903-1938$ & wdc & $\ldots$ \\
\hline DOU & Dourbes & 50.097 & 4.595 & $1964-1988$ & obs & $\cdots$ \\
\hline DRV & Dumont d'Urville & -66.665 & 140.007 & $1962-1991$ & bcmt & $\cdots$ \\
\hline $\mathrm{EBR}$ & Ebro & 40.820 & 0.493 & $1910-1937$ & obs & $\ldots$ \\
\hline$\cdots$ & $\cdots$ & $\cdots$ & $\cdots$ & $1950-1981$ & obs & $\cdots$ \\
\hline ESK & Eskdalemuir & 55.317 & 356.800 & 1911-1994 & obs & .. \\
\hline FCC & Fort Churchill & 58.767 & 265.900 & 1964-1994 & wdc & $\ldots$ \\
\hline FRD & Fredericksburg & 38.205 & 282.627 & 1901-1989 & wdc & 1957 \\
\hline FUQ & Fuquene & 5.470 & 286.263 & $1954-1994$ & obs & $\ldots$ \\
\hline FUR & Furstenfeldbruck & 48.165 & 11.277 & $1940-1993$ & obs & $\cdots$ \\
\hline $\mathrm{GDH}$ & Godhavn & 69.252 & 306.467 & $1926-1993$ & wdc & 1975 \\
\hline GNA & Gnangara & -31.783 & 115.950 & 1919-1992 & obs & 1958 \\
\hline GUA & Guam & 13.583 & 144.870 & $1958-1980$ & wdc & $\cdots$ \\
\hline GWC & Great Whale River & 55.267 & 282.217 & $1966-1984$ & wdc & $\cdots$ \\
\hline HAD & Hartland & 50.995 & 356.517 & $1926-1993$ & obs & $\ldots$ \\
\hline HBK & Hartebeeshoek & -25.882 & 27.707 & $1964-1986$ & obs & $\cdots$ \\
\hline HER & Hermanus & -34.425 & 19.225 & $1941-1993$ & obs & $\cdots$ \\
\hline HLP & Hel & 54.608 & 18.815 & $1966-1993$ & obs & $\ldots$ \\
\hline HON & Honolulu & 21.320 & 201.998 & $1902-1976$ & obs & 1947,1960 \\
\hline HRB & Hurbanovo & 47.873 & 18.190 & $1893-1914$ & obs & $\ldots$ \\
\hline$\cdots$ & $\cdots$ & $\cdots$ & $\cdots$ & 1949-1994 & $\cdots$ & $\ldots$ \\
\hline $\mathrm{HRN}$ & Hornsund & 77.000 & 15.550 & $1978-1993$ & obs & .. \\
\hline HUA & Huancayo & -12.045 & 286.660 & $1922-1989$ & obs & $\ldots$ \\
\hline HYB & Hyderabad & 17.413 & 78.555 & $1965-1991$ & obs & $\cdots$ \\
\hline IRT & Patrony & 52.167 & 104.450 & $1959-1990$ & obs & 1977 \\
\hline KAK & Kakioka & 36.230 & 140.190 & $1897-1917$ & obs & $\cdots$ \\
\hline$\ldots$ & & $\ldots$ & $\ldots$ & $1924-1993$ & obs & 1958 \\
\hline KIV & Kiev (Dymer) & 50.717 & 30.300 & 1958-1992 & obs & 1964 \\
\hline KNY & Kanoya & 31.420 & 130.882 & $1958-1993$ & wdc & $\ldots$ \\
\hline KOD & Kodaikanal & 10.230 & 77.463 & $1965-1991$ & obs & $\ldots$ \\
\hline LAS & Las Acacias & -35.007 & 302.310 & $1962-1993$ & obs & $\cdots$ \\
\hline LER & Lerwick & 60.133 & 358.817 & $1926-1993$ & wdc & $\cdots$ \\
\hline LNN & Voyeykovo & 59.950 & 30.705 & $1947-1985$ & wdc & 1963 \\
\hline LRV & Leirvogur & 64.183 & 338.300 & $1953-1994$ & obs & $\ldots$ \\
\hline LVV & Lvov & 49.900 & 23.750 & $1953-1978$ & wdc & 1969 \\
\hline MAW & Mawson & -67.600 & 62.880 & 1961-1992 & obs & $\ldots$ \\
\hline $\mathrm{MBC}$ & Mould Bay & 76.200 & 240.600 & $1963-1994$ & wdc & $\cdots$ \\
\hline MBO & M'Bour & 14.392 & 343.042 & $1952-1991$ & bcmt & $\cdots$ \\
\hline MCQ & Macquarie Island & -54.500 & 158.950 & 1961-1993 & obs & $\cdots$ \\
\hline MEA & Meanook & 54.617 & 246.667 & $1932-1994$ & wdc & $\ldots$ \\
\hline
\end{tabular}


Table 2a. (continued)

\begin{tabular}{|c|c|c|c|c|c|c|}
\hline Code $^{a}$ & Name & $\lambda^{b}$ & $\varphi^{c}$ & Period $^{d}$ & Source $e^{e}$ & $\mathrm{Jump}^{f}$ \\
\hline MMB & Memambetsu & 43.907 & 144.193 & 1958-1994 & wdc & \\
\hline MMK & Loparskoye & 68.250 & 33.083 & $1959-1980$ & wdc & 1961,1965 \\
\hline MNK & Pleshenitzi & 54.500 & 27.883 & $1961-1990$ & wdc & $\ldots$ \\
\hline MOS & Krasnaya Pakhra & 55.467 & 37.312 & $1947-1988$ & wdc & . \\
\hline NEW & Newport & 48.263 & 242.880 & $1966-1989$ & wdc & $\ldots$ \\
\hline NGK & Niemegk & 52.072 & 12.675 & $1890-1994$ & obs & $\ldots$ \\
\hline NUR & Nurmijarvi & 60.508 & 24.655 & 1953-1994 & obs & $\cdots$ \\
\hline NVS & Klyuchi & 55.033 & 82.900 & $1966-1989$ & wdc & 1972 \\
\hline ODE & Stepanovka & 46.783 & 30.883 & $1948-1981$ & obs & \\
\hline PAF & Port-aux-Français & -49.350 & 70.200 & 1958-1991 & bcmt & 1980 \\
\hline PAG & Panagyuriste & 42.512 & 24.177 & $1956-1992$ & obs & 1962 \\
\hline PMG & Port Moresby & -9.408 & 147.150 & 1958-1988 & wdc & \\
\hline POD & Podkamennaya & 61.600 & 90.000 & $1969-1990$ & wdc & .. \\
\hline PPT & Pamataï & -17.568 & 210.425 & 1969-1991 & bcmt & $\ldots$ \\
\hline RES & Resolute Bay & 74.100 & 265.100 & 1954-1994 & obs & 1967 \\
\hline SAB & Sabhawala & 30.363 & 77.798 & 1965-1991 & obs & \\
\hline SBA & Scott Base & -77.850 & 166.783 & 1964-1989 & wdc & $\ldots$ \\
\hline SIT & Sitka & 57.058 & 224.675 & $1902-1993$ & wdc & $\ldots$ \\
\hline SJG & San Juan & 18.113 & 293.85 & $1926-1993$ & wdc & 1965 \\
\hline SOD & Sodankyla & 67.368 & 26.6300 & 1914-1945 & wdc & 1945 \\
\hline & & & $\ldots$ & $1946-1993$ & $\ldots$ & $\ldots$ \\
\hline SPA & South Pole & -89.993 & 346.678 & 1959-1971 & wdc & $\ldots$ \\
\hline SUA & Surlari & 44.680 & 26.253 & $1949-1993$ & obs & $\ldots$ \\
\hline TEO & Teoloyucan & 19.747 & 260.818 & $1960-1978$ & obs & $\ldots$ \\
\hline TFS & Dusheti & 42.092 & 44.705 & 1959-1992 & wdc & $\cdots$ \\
\hline THL & Thule & 77.483 & 290.833 & 1959-1988 & wdc & $\ldots$ \\
\hline THY & Tihany & 46.900 & 17.893 & $1955-1987$ & obs & 1979 \\
\hline TOO & Toolangi & -37.530 & 145.470 & $1953-1979$ & obs & $\ldots$ \\
\hline TRD & Trivandrum & 8.483 & 76.950 & 1958-1991 & obs & $\ldots$ \\
\hline TRW & Trelew & -43.248 & 294.685 & $1957-1992$ & obs & $\ldots$ \\
\hline TSU & Tsumeb & -19.217 & 17.700 & $1964-1989$ & obs & $\ldots$ \\
\hline TUC & Tucson & 32.247 & 249.167 & $1910-1993$ & wdc & $\ldots$ \\
\hline VAL & Valentia & 51.933 & 349.750 & $1954-1993$ & obs & $\ldots$ \\
\hline VIC & Victoria & 48.517 & 236.583 & $1964-1994$ & wdc & $\ldots$ \\
\hline VQS & Vieques & 18.147 & 294.552 & $1903-1925$ & wdc & $\ldots$ \\
\hline WIK & Wien Kobenzl & 48.265 & 16.318 & $1956-1994$ & obs & $\cdots$ \\
\hline WIT & Witteveen & 52.813 & 6.668 & $1938-1987$ & wdc & $\ldots$ \\
\hline WNG & Wingst & 53.743 & 9.073 & 1939-1993 & obs & $\cdots$ \\
\hline
\end{tabular}

${ }^{a}$ According to the International Association of Geomagnetism and Aeronomy (IAGA) convention.

${ }^{b}$ Latitude of the observatory, in degrees.

${ }^{c}$ Longitude of the observatory, in degrees, positive eastward.

${ }^{d}$ Interval of time with uninterrupted $X$ and $Y$ series.

${ }^{e}$ Data retrieved from bcmt, Bureau Central de Magnétisme Terrestre (Institut de Physique du Globe, Paris, France); wdc, World Data Center (Boulder, Colorado); obs, data supplied by the observatory.

${ }^{f}$ Dates of changes in the baselines.

detected, we carefully checked the consistency of the monthly mean values with the annual mean values on the same CD-ROM (labeled NGDC 05/1) by computing the annual means from the monthly means and comparing them with the archived values. This revealed that in some observatories and at certain epochs changes in the base level had been applied to the annual means (indicated by " $\mathrm{J}$ " in the file called "annual" on NGDC CD-ROM) but not to the monthly means. We corrected for this, by simply applying the required changes to the monthly series. When this correction did not give satisfying results, more information was directly requested from the observatories; several of them acknowledged that corrections due to changes in instrumental baselines had been omitted.

The lists of available observatories with the corre- sponding code, geographical coordinates, lengths of time series and baseline corrections are given in Tables 2a and $2 \mathrm{~b}$ (note that further useful data might still be obtained from other observatories). The geographical distribution of these observatories is shown on Figure 3. Let us emphasize that the process of establishing sound time series in the way just described, however time consuming, is both an essential step to the following analysis and a very efficient way of identifying possible problems within the observatory data.

\section{Results}

The same analysis procedure as the one used previously for the synthetic tests has been applied to the $X$ and $Y$ series of the 97 observatories of Table 2a. Only a 
Table 2b. Corrections Made to Observatory Baselines in This Study

\begin{tabular}{|c|c|c|c|c|c|}
\hline $\operatorname{Code}^{a}$ & Name & Jump Date ${ }^{b}$ & $X^{c}$ & $Y^{d}$ & $Z^{e}$ \\
\hline $\mathrm{AGN}$ & Agincourt & 1958 & -239 & -547 & 56 \\
\hline $\mathrm{BFE}$ & Brorfelde & 1982 & 137 & -1 & -266 \\
\hline BLC & Baker Lake & 1969 & 93 & -88 & 8 \\
\hline BLC & Baker Lake & 1975 & -60 & 95 & 3 \\
\hline BLC & Baker Lake & 1977 & -6 & 0 & 60 \\
\hline BNG & Bangui & 1957 & -111 & 9 & 27 \\
\hline CLF & Chambon la Forêt & 1957 & -34 & 4 & -70 \\
\hline CLF & Chambon la Forêt & 1968 & 1 & 17 & -11 \\
\hline CLF & Chambon la Forêt & 1983 & 1 & 0 & 1 \\
\hline CMO & College & 1947 & 22 & -49 & 100 \\
\hline FRD & Fredericksburg & 1957 & 471 & 186 & -413 \\
\hline GDH & Godhavn & 1975 & 40 & -36 & 275 \\
\hline GNA & Gnangara & 1958 & -909 & -50 & -1269 \\
\hline HON & Honolulu & 1947 & 224 & 602 & -237 \\
\hline HON & Honolulu & 1960 & -244 & -88 & -421 \\
\hline IRT & Patrony & 1977 & 4 & 8 & 8 \\
\hline KAK & Kakioka & 1958 & 11 & -19 & -44 \\
\hline KIV & Kiev (Dymer) & 1964 & 43 & -104 & -10 \\
\hline LNN & Voyeykovo & 1963 & 17 & -6 & 15 \\
\hline LVV & Lvov & 1969 & 0 & 0 & 36 \\
\hline MMK & Loparskoye & 1961 & 150 & 207 & -270 \\
\hline MMK & Loparskoye & 1965 & -1 & 0 & 30 \\
\hline NVS & Klyuchi & 1972 & 6 & 1 & 5 \\
\hline PAF & Port-aux-Françajs & 1980 & 0 & 0 & 1 \\
\hline PAG & Panagyuriste & 1962 & $\mathbf{0}$ & -2 & 0 \\
\hline RES & Resolute Bay & 1967 & -10 & 5 & -10 \\
\hline SJG & San Juan & 1965 & -83 & 207 & -257 \\
\hline SOD & Sodankyla & 1945 & -13 & -25 & -124 \\
\hline THY & Tihany & 1979 & 0 & 0 & 20 \\
\hline
\end{tabular}

${ }^{a}$ According to the IAGA convention.

${ }^{b}$ According to Table 2a.

${ }^{c}$ Correction applied to $\mathrm{X}$ component, in nanotesla.

${ }^{d}$ Correction applied to $\mathrm{Y}$ component, in nanotesla.

${ }^{e}$ Correction applied to $\mathrm{Z}$ component, in nanotesla.

small number of observatories have long enough records to allow for the detection of the jerks occurring during the first quarter of the century. The whole set of results is given in Tables 3a-g; the dates found for the jerks cluster into seven groups hereinafter referred to as the $1901,1913,1925,1932,1949,1969$, and 1978 events (Figure 4). For each of the seven jerks detected in the data series, the extinction angle $\theta_{e}$ can be determined with the same accuracy as in the case of the synthetic tests.

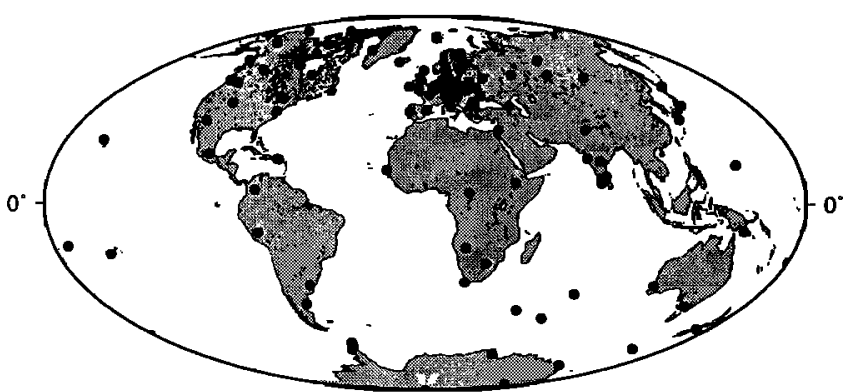

Figure 3. Distribution of the 97 observatories considered in the present study. See also Table 2a for more details.

\section{Early Events}

The 1901 event was successfully detected in all observatories with available data for this epoch. It clearly appears, with well-defined ridge functions of type 1 , in three European observatories (CLF, COI, NGK, see Table $3 \mathrm{a}$ and Figure 5). It is also present, as a late edge of an energy packet (see the appendix for more details), in the wavelet transforms of the HRB and KAK series. However, the insufficient duration of the records for these two observatories (compare Table 2a) did not allow us to recover the ridge functions over a large range of dilations. Dates $(1902.0 \pm 0.5)$ and regular-

Table 3a. Results for the 1901 Event

\begin{tabular}{ccccc}
\hline$\theta^{a}$ & $\theta_{b}{ }^{b}$ & $\alpha^{c}$ & Date $^{d}$ & Code \\
\hline 125 & 90 & 1.60 & 1901.33 & CLF \\
120 & 70 & 1.66 & 1902.60 & COI \\
130 & 80 & 1.55 & 1902.17 & NGK \\
\hline
\end{tabular}

${ }^{a}$ Direction angle of the jerk in degrees.

${ }^{b}$ Enhancement angle of the jerk in degrees.

${ }^{c}$ Slope of the ridge function.

${ }^{d}$ Date of occurrence of the jerk. 
Table 3b. Results for the 1913 Event

\begin{tabular}{rrrrl}
\hline$\theta^{a}$ & $\theta_{b}{ }^{b}$ & $\alpha^{c}$ & Date $^{d}$ & Code \\
\hline 65 & 90 & 1.41 & 1913.92 & BFE \\
140 & 90 & 1.47 & 1913.17 & CLF \\
120 & 80 & 1.35 & 1911.14 & COI \\
130 & 90 & 1.37 & 1915.17 & DBN \\
165 & 50 & 1.28 & 1913.33 & FRD \\
160 & 60 & 1.26 & 1913.17 & HON \\
140 & 90 & 1.60 & 1913.75 & NGK \\
25 & 110 & 1.61 & 1915.05 & SIT \\
25 & 90 & 1.42 & 1913.67 & VQS \\
\hline
\end{tabular}

${ }^{a}$ Direction angle of the jerk in degrees.

${ }^{b}$ Enhancement angle of the jerk in degrees.

${ }^{\mathrm{c}}$ Slope of the ridge function.

${ }^{d}$ Date of occurrence of the jerk.

ities ( $\alpha=1.60 \pm 0.04$ ) found for this jerk are almost identical for the three observatories where they could be computed. It seems safe to conclude that the 1901 jerk is observed in a large part of the northern hemisphere, but it may be of worldwide extent.

The 1913 event has also been detected in all observatories with sufficient data (see Table 2a). It is clearly observed in five European (BFE, CLF, COI, DBN, NGK) and three North American (FRD, SIT, VQS) observatories and HON (Table $3 \mathrm{~b}$ and Figure 6). Most dates of this jerk cluster at the average date (1913.6 \pm 1.1 ). However, the dates of the event at COI and DBN are surprisingly far from the average. The regularities estimated from the nine ridge functions (Figure 6) give an average of $1.42 \pm 0.12$. This event again could very well be worldwide.

The 1925 event is clearly observed at five European observatories (BFE, CLF, DBN, ESK, NGK) and two North American ones (TUC and SIT), but not at FRD (Table $3 \mathrm{c}$ and Figure 7). This jerk has also been detected for the remaining observatories EBR and SOD (with less data) as an energy packet in the wavelet transform. The average date and regularity are $1925.2 \pm$ 0.8 and $1.64 \pm 0.19$, respectively. This event could again be worldwide.

The 1932 event does not show up everywhere. It is detected at the FRD and HON observatories and in the

Table 3c. Results for the 1925 Event

\begin{tabular}{rrrrl}
\hline$\theta^{a}$ & $\theta_{b}^{b}$ & $\alpha^{c}$ & Date $^{d}$ & Code \\
\hline 60 & 80 & 1.48 & 1925.08 & BFE \\
55 & 80 & 1.67 & 1924.08 & CLF \\
50 & 50 & 1.84 & 1924.25 & DBN \\
45 & 80 & 1.90 & 1926.42 & ESK \\
55 & 80 & 1.52 & 1925.50 & NGK \\
50 & 110 & 1.33 & 1925.52 & SIT \\
115 & 90 & 1.73 & 1925.50 & TUC \\
\hline
\end{tabular}

${ }^{a}$ Direction angle of the jerk in degrees.

${ }^{b}$ Enhancement angle of the jerk in degrees.

${ }^{c}$ Slope of the ridge function.

${ }^{d}$ Date of occurrence of the jerk.
Table 3d. Results for the 1932 Event

\begin{tabular}{rrrrl}
\hline$\theta^{a}$ & $\theta_{b}{ }^{b}$ & $\alpha^{c}$ & Date $^{d}$ & Code \\
\hline 85 & 110 & 1.92 & 1932.08 & AML \\
45 & 90 & 1.55 & 1931.75 & API \\
10 & 50 & 1.57 & 1932.00 & FRD \\
25 & 80 & 1.60 & 1930.58 & GNA \\
60 & 80 & 1.65 & 1933.83 & HON \\
50 & 80 & 1.46 & 1934.08 & HUA \\
\hline
\end{tabular}

${ }^{a}$ Direction angle of the jerk in degrees.

bnhancement angle of the jerk in degrees.

${ }^{c}$ Slope of the ridge function.

${ }^{d}$ Date of occurrence of the jerk.

southern hemisphere at the four observatories (AML, API, GNA and HUA) whose time series are long enough to allow for such a detection (Table 3d and Figure 8). The average date and regularity found for this jerk are $1932.4 \pm 1.2$ and $1.63 \pm 0.14$, respectively. This event is not seen in any of the European observatories.

The 1949 event is again not seen in Europe. It is observed in the Pacific area (ABG, AML, API, GNA, $\mathrm{KAK}$ ) and in the American region (FRD, HON, HUA, SJG, TUC) (Table 3e and Figure 9). The average date and regularity estimated for this event are 1949.8 \pm 1.4 and $1.49 \pm 0.27$, respectively. The 1949 jerk covers the same geographical area as the 1932 event. We will not discuss any further those early events which are much less documented than the 1969 and 1978 ones, on which we will now focus.

\section{The 1969 and 1978 Events}

The worldwide character of the 1969 event is attested by its presence in a large number of observatories distributed all around the world (at 66 observatories out of the 74 covering the time span around the event (Table 2a)). The ridge functions of this jerk are very clear for 47 observatories where they are linear over a large dilation range (Table $3 \mathrm{f}$ and Figure 10). We note evidence of this jerk in the form of conelike energy patches in the wavelet transforms of the series at 19 other ob-

Table 3e. Results for the 1949 Event

\begin{tabular}{rrrrl}
\hline$\theta^{a}$ & $\theta_{b}{ }^{b}$ & $\alpha^{c}$ & Date $^{d}$ & Code \\
\hline 30 & 80 & 1.78 & 1947.67 & ABG \\
75 & 80 & 1.36 & 1949.08 & AML \\
30 & 70 & 1.00 & 1949.25 & API \\
170 & 50 & 1.64 & 1950.00 & FRD \\
120 & 100 & 1.63 & 1949.83 & GNA \\
165 & 60 & 1.39 & 1950.83 & HON \\
115 & 170 & 1.44 & 1951.58 & HUA \\
120 & 100 & 1.13 & 1949.67 & KAK \\
170 & 40 & 1.83 & 1952.42 & SJG \\
155 & 100 & 1.74 & 1947.83 & TUC \\
\hline
\end{tabular}

${ }^{a}$ Direction angle of the jerk in degrees.

${ }^{b}$ Enhancement angle of the jerk in degrees.

${ }^{c}$ Slope of the ridge function.

${ }^{d}$ Date of occurrence of the jerk. 
Table 3f. Results for the 1969 Event

\begin{tabular}{|c|c|c|c|c|c|}
\hline $\operatorname{Sign}^{a}$ & $\theta^{b}$ & $\theta_{b}^{c}$ & $\alpha^{d}$ & $\operatorname{Date}^{e}$ & Code \\
\hline+ & 25 & 160 & 1.52 & 1972.33 & ANN \\
\hline+ & 25 & 70 & 1.37 & 1971.84 & API \\
\hline+ & 80 & 80 & 1.30 & 1968.83 & AQL \\
\hline+ & 95 & 80 & 1.70 & 1969.42 & BFE \\
\hline+ & 95 & 90 & 1.64 & 1969.09 & CLF \\
\hline - & 60 & 120 & 1.46 & 1969.75 & CMO \\
\hline+ & 95 & 90 & 1.58 & 1969.50 & COI \\
\hline+ & 100 & 100 & 1.90 & 1968.92 & EBR \\
\hline+ & 90 & 80 & 1.71 & 1968.67 & ESK \\
\hline- & 160 & 50 & 1.46 & 1969.42 & FRD \\
\hline+ & 95 & 80 & 1.69 & 1969.09 & FUR \\
\hline+ & 30 & 90 & 1.70 & 1968.83 & GDH \\
\hline+ & 30 & 80 & 1.65 & 1972.59 & GNA \\
\hline+ & 90 & 90 & 1.77 & 1969.42 & HAD \\
\hline- & 145 & 110 & 1.07 & 1972.42 & HER \\
\hline- & 40 & 80 & 1.21 & 1972.67 & HUA \\
\hline- & 80 & 60 & 1.71 & 1969.17 & IRT \\
\hline- & 110 & 90 & 1.36 & 1969.42 & KAK \\
\hline+ & 90 & 80 & 1.96 & 1970.42 & KIV \\
\hline- & 115 & 110 & 1.86 & 1970.33 & KNY \\
\hline+ & 85 & 100 & 1.53 & 1969.09 & LER \\
\hline+ & 85 & 80 & 1.55 & 1969.58 & LNN \\
\hline+ & 85 & 90 & 1.73 & 1969.25 & L.RV \\
\hline+ & 100 & 90 & 2.05 & 1969.17 & LVV \\
\hline+ & 90 & 130 & 1.56 & 1970.09 & MBO \\
\hline- & 75 & 110 & 1.58 & 1970.42 & MEA \\
\hline - & 160 & 100 & 1.87 & 1970.08 & MMB \\
\hline+ & 95 & 100 & 1.92 & 1970.08 & MMK \\
\hline+ & 90 & 110 & 1.60 & 1969.50 & MOS \\
\hline+ & 80 & 90 & 1.74 & 1969.09 & NGK \\
\hline+ & 90 & 90 & 1.73 & 1969.25 & NUR \\
\hline+ & 100 & 100 & 1.82 & 1969.17 & ODE \\
\hline+ & 70 & 80 & 1.46 & 1969.42 & PAG \\
\hline+ & 35 & 90 & 1.43 & 1971.92 & PMG \\
\hline- & 65 & 80 & 1.55 & 1968.92 & RES \\
\hline- & 65 & 110 & 1.82 & 1969.73 & SIT \\
\hline+ & 25 & 90 & 1.00 & 1968.84 & SJG \\
\hline+ & 85 & 90 & 1.66 & 1969.42 & SOD \\
\hline+ & 70 & 90 & 1.22 & 1968.75 & SUA \\
\hline+ & 75 & 70 & 1.65 & 1968.75 & TFS \\
\hline+ & 90 & 90 & 1.45 & 1970.92 & THY \\
\hline+ & 10 & 160 & 1.32 & 1971.75 & TRD \\
\hline- & 40 & 80 & 1.41 & 1971.25 & TUC \\
\hline+ & 90 & 100 & 1.95 & 1969.33 & VAL \\
\hline+ & 85 & 80 & 1.86 & 1970.00 & WIK \\
\hline+ & 85 & 90 & 1.68 & 1969.59 & WIT \\
\hline+ & 90 & 90 & 1.83 & 1969.00 & WNG \\
\hline
\end{tabular}

servatories (despite their limited records), distributed worldwide (ABG, AML, BLC, DOU, FCC, FUQ, GUA, HBK, HRB, LAS, MAW, MBC, MCQ, MNK, PAF, TEO, THL, TOO, TSU).

The 1978 event displays the same global character, being visible at 71 observatories out of 78 . It is detected and shows clear ridge function signatures in 46 observatories, distributed worldwide (Table $3 \mathrm{~g}$ and Figure 11). For 25 other observatories the event is located close to the beginning or the end of the available series (ABG, ANN, BNG, BRW, DRV, FUQ, HBK, HYD, IRT, KOD, LAS, MBC, MBO, MNK, NVS, PMG, POD, PPT, RES, SAB, SUA, TFS, TRD, TRW, TSU). For all these observatories the event is detected from energy patches in the wavelet transforms.

A very interesting feature revealed by this analysis is that the distribution of the dates of occurrence is clearly bimodal (Figure 12) for both events. For the 1969 event a first group of dates is centered on $1969.4 \pm 0.5$ and an-

Table 3g. Results for the 1978 Event

\begin{tabular}{|c|c|c|c|c|c|}
\hline $\operatorname{Sign}^{a}$ & $\theta^{b}$ & $\theta_{b}^{c}$ & $\alpha^{d}$ & Date $^{e}$ & Code \\
\hline - & 40 & 80 & 1.88 & 1978.25 & API \\
\hline - & 90 & 80 & 1.05 & 1978.00 & AQL \\
\hline- & 90 & 80 & 1.29 & 1978.00 & BEL \\
\hline - & 60 & 80 & 1.46 & 1978.09 & $\mathrm{BFE}$ \\
\hline+ & 50 & 90 & 1.60 & 1978.17 & BLC \\
\hline+ & 45 & 100 & 1.38 & 1978.67 & $\mathrm{BOU}$ \\
\hline- & 60 & 80 & 1.89 & 1978.59 & CLF \\
\hline- & 40 & 100 & 1.01 & 1977.67 & $\mathrm{COI}$ \\
\hline - & 45 & 80 & 1.09 & 1981.75 & $\mathrm{CZT}$ \\
\hline - & 40 & 80 & 1.53 & 1978.00 & DOU \\
\hline- & 40 & 80 & 1.37 & 1977.59 & ESK \\
\hline+ & 65 & 100 & 1.73 & 1977.92 & FCC \\
\hline+ & 45 & 70 & 1.64 & 1978.09 & FRD \\
\hline - & 40 & 80 & 1.83 & 1978.00 & FUR \\
\hline - & 160 & 50 & 1.81 & 1976.84 & GDH \\
\hline+ & 25 & 90 & 1.78 & 1980.92 & GNA \\
\hline - & 45 & 90 & 1.64 & 1978.09 & HAD \\
\hline - & 45 & 90 & 1.36 & 1982.00 & HER \\
\hline - & 85 & 90 & 1.50 & 1980.80 & HLP \\
\hline- & 90 & 80 & 1.79 & 1978.50 & HRB \\
\hline+ & 145 & 110 & 1.63 & 1977.84 & KAK \\
\hline - & 70 & 70 & 1.51 & 1977.75 & KIV \\
\hline+ & 155 & 100 & 1.85 & 1979.33 & KNY \\
\hline - & 45 & 80 & 1.67 & 1977.92 & LER \\
\hline - & 50 & 90 & 1.42 & 1977.58 & LRV \\
\hline- & 100 & 70 & 1.97 & 1976.42 & LNN \\
\hline- & 65 & 120 & 1.28 & 1978.00 & MCQ \\
\hline+ & 75 & 110 & 1.78 & 1976.67 & MEA \\
\hline+ & 155 & 100 & 1.52 & 1977.83 & MMB \\
\hline- & 110 & 40 & 1.89 & 1976.50 & MOS \\
\hline+ & 65 & 90 & 1.95 & 1978.37 & NEW \\
\hline - & 50 & 80 & 1.69 & 1978.17 & NGK \\
\hline - & 40 & 90 & 1.40 & 1977.67 & NUR \\
\hline+ & 50 & 70 & 1.58 & 1981.92 & PAF \\
\hline- & 35 & 90 & 1.51 & 1977.75 & PAG \\
\hline+ & 50 & 100 & 1.58 & 1977.71 & SIT \\
\hline+ & 55 & 70 & 1.72 & 1977.92 & SJG \\
\hline - & 25 & 80 & 1.65 & 1978.09 & SOD \\
\hline - & 10 & 40 & 1.63 & 1976.67 & THL \\
\hline- & 60 & 90 & 1.44 & 1977.67 & THY \\
\hline+ & 50 & 80 & 1.66 & 1978.00 & TUC \\
\hline - & 45 & 90 & 1.74 & 1978.25 & VAL \\
\hline+ & 60 & 80 & 1.76 & 1977.58 & VIC \\
\hline- & 40 & 80 & 1.83 & 1979.00 & WIK \\
\hline- & 25 & 80 & 1.78 & 1978.17 & WIT \\
\hline - & 45 & 80 & 1.65 & 1978.25 & WNG \\
\hline
\end{tabular}

${ }^{a}$ The sign of jerk detected from the wavelet maps.

${ }^{b}$ Direction angle of the jerk in degrees.

${ }^{c}$ Enhancement angle of the jerk in degrees.

${ }^{d}$ Slope of the ridge function.

e Date of occurrence of the jerk. 


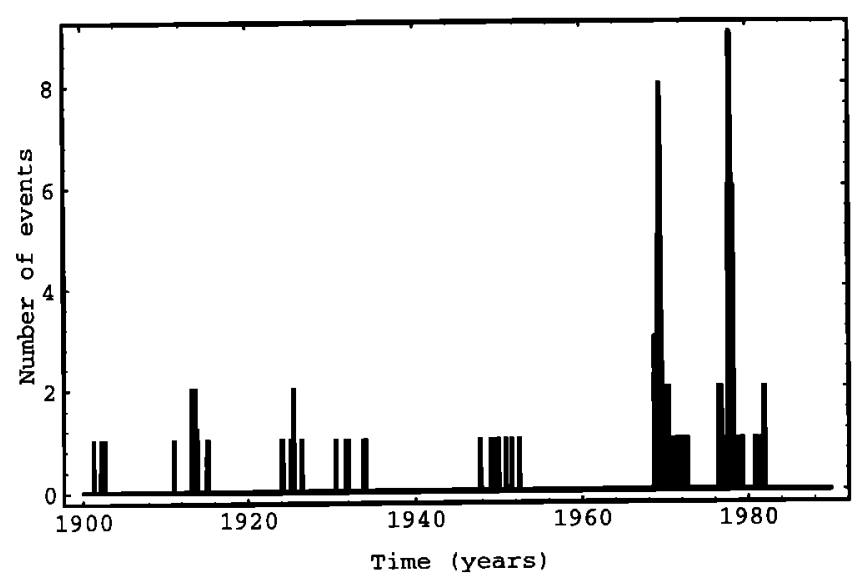

Figure 4. Histogram of the dates of the jerks detected in the present study. Seven clusters can be identified, roughly dated 1901, 1913, 1925, 1932, 1949, 1969, and 1978.

other one on $1972.1 \pm 0.5$. In a similar way, the dates of the 1978 event split into a first group centered on $1977.9 \pm 0.6$ and a second one centered on $1981.5 \pm 0.5$. Figure 13, which shows the geographical distribution of the dates of occurrence, further reveals that the bimodal temporal distribution of the 1969 jerk is also associated with a clear geographical pattern: the jerk appears at a later date in the southern hemisphere. This result is corroborated by the analysis of the wavelet maps of eight other observatories located in the southern hemisphere (FUQ, HBK, LAS, MAW, MCQ, PAF, TOO, and TSU) and for which the examination of the energy packet also suggests a date around 1972. Figure 14 shows that exactly the same thing happens to be true for the 1978 event. The occurrence time is again later in the southern than in the northern hemisphere with a similar time lag of about 2 to 3 years (note, however, that the number of analyzed southern series is even smaller than for the 1969 event). Again also, this later date is confirmed by inspecting the conelike energy patches typical of jerks within the wavelet maps of 12 additional observatories with shorter series (ABG, ANN, DRV, FUQ, HBK, HYD, KOD, LAS, PMG, PPT, TRW, and TSU). Thus the two 1969 and 1978 events seem to share a common spatio-temporal behavior.

To what extent can this similarity be generalized to the regularity $\alpha$ and the local direction $\theta$, both param-
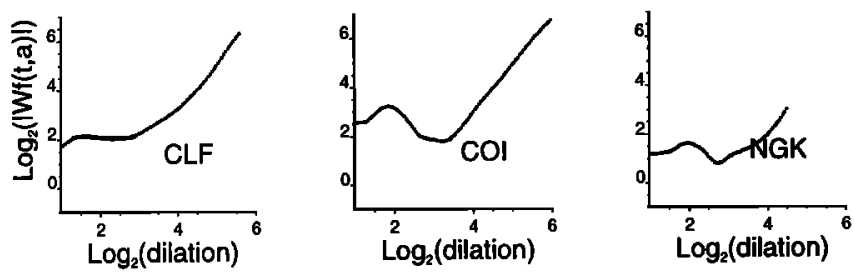

Figure 5. Log-log plots of the ridge functions of the 1901 event (see Table 2a for the code and location of the observatories and Table 3a for ridge function slopes).
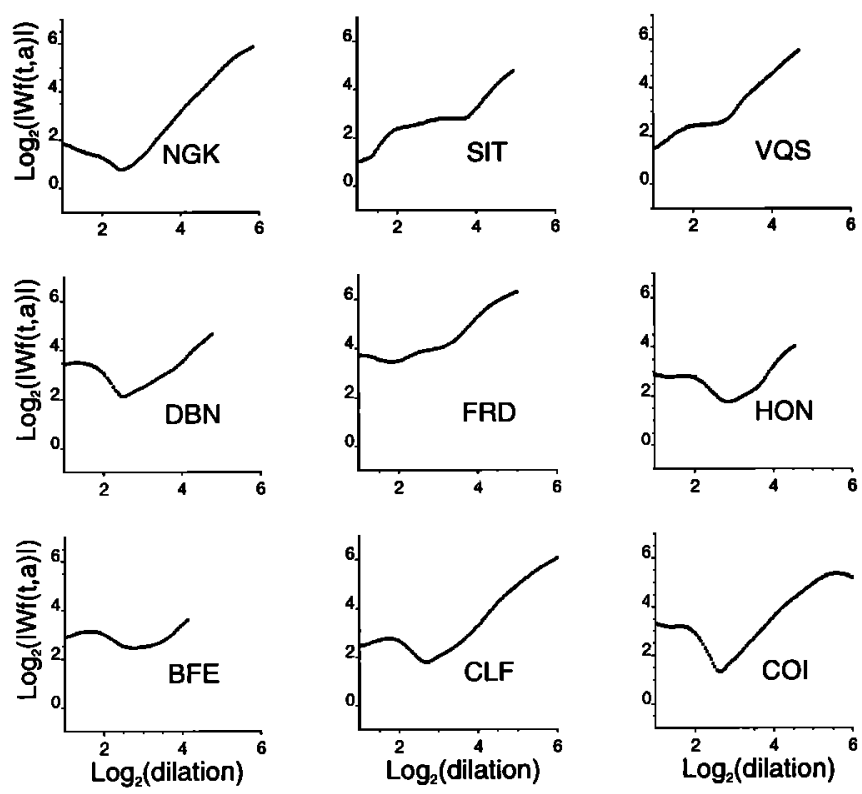

Figure 6. Log-log plots of the ridge functions of the 1913 event (see Table 2a for the code and location of the observatories and Table $3 \mathrm{~b}$ for ridge function slopes).

eters being available at 47 observatories for the 1969 event, and 46 observatories for the 1978 event? We note that the average values of the $\alpha$ for 1969 and 1978 events happen to be equal $(\alpha=1.6)$. But we also note that within each event, the measured values of $\alpha$ vary significantly from place to place (Tables $3 \mathrm{f}$ and $3 \mathrm{~g}$ ). We measured this dispersion in terms of a global standard deviation with respect to the previous average values. Again we found exactly the same value $\sigma_{\alpha}=0.23$ for both events. This value is slightly larger than the standard deviation we expected from our synthetic test
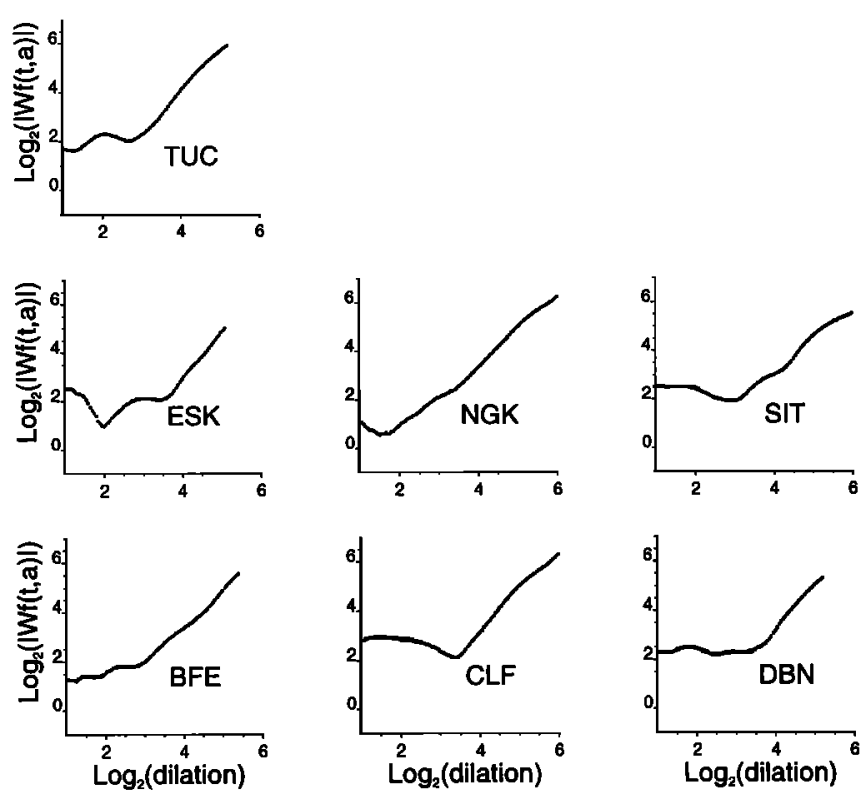

Figure 7. Log-log plots of the ridge functions of the 1925 event (see Table 2a for the code and location of the observatories and Table $3 \mathrm{c}$ for ridge function slopes). 

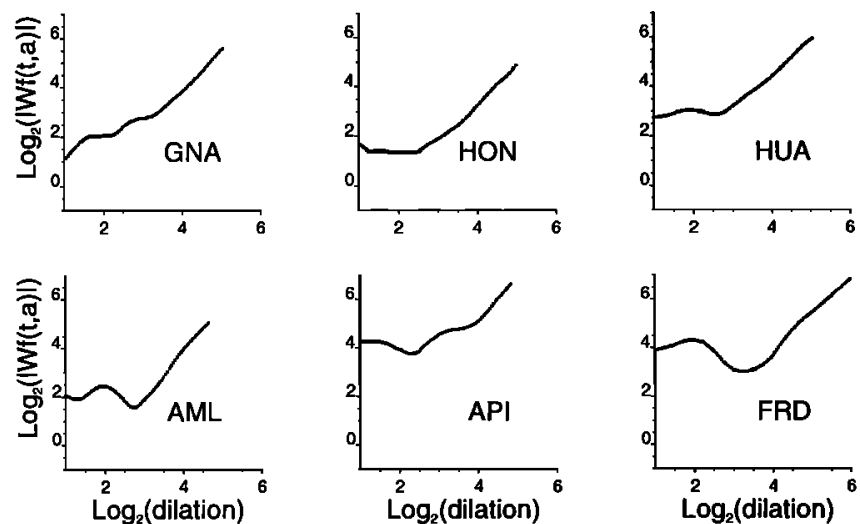

Figure 8. Log-log plots of the ridge functions of the 1932 event (see Table $2 a$ for the code and location of the observatories and Table $3 \mathrm{~d}$ for ridge function slopes).

(which suggests a value of the order of 0.15 ; recall Table 1). This could result from the way we estimated the error in $\alpha$ in the synthetic case using only data from close-by European observatories. However, it could also be due to some geophysically relevant regional variations. In order to check this, we produced maps of the departures of the $\alpha$ from the average value 1.6 for each of the two events (Figures 15 and 16). The 1969 event again displays a fairly strong global asymmetry, with the southern hemisphere (crudely speaking) usually showing regularities below the average value, while the northern hemisphere tends to reveal larger regularities. This asymmetry is less obvious for the 1978 event, but this might be due to the tiny number of values recoverable from the southern hemisphere. Hence we may conclude that within the accuracy of our method, the regularities of the two events seem to be identical, with an average value of $\alpha=1.61 \pm 0.23$, and a common tendency to be slightly larger in the northern than in the southern hemisphere.

The local directions for both jerks (sign and $\theta$ in Tables $3 \mathrm{f}$ and $3 \mathrm{~g}$ ) are displayed on maps (Figures 17 and 18). In interpreting these maps, one must carefully keep in mind that they give no information about the intensity of the signal, $|\beta|$, a parameter we have not yet been able to recover in a systematic way (which remains a drawback of the present study but will be the subject of further investigation). Both maps show satisfactory regional consistency and reveal that the two events are not simple in geometry. They appear to be large scale but complex phenomena. There is no simple north-south symmetry or antisymmetry. A comparison between the two events shows that in most places the 1978 directions tend to be opposite to the 1969 directions. Figure 19 is a blow up of the planetary map over Europe; the arrows are indeed well organized, have approximately the same directions, but reverse senses in 1969 and 1978.

\section{Concluding Remarks}

In paper 1 we focused on the analysis of the $Y$ component observed in European observatories. This allowed us to uncover five events in the twentieth century, to confirm their internal origin, and to show that they are more singular than previously assumed, with a regularity closer to 1.5 than to 2 . The present study confirms and extends these early results.

Allowing for the search to be carried out on any horizontal component made it, for instance, possible to detect the 1978 event which was not seen at GDH observatory when analyzing the $Y$ component (paper 1). It is now seen there on the $\mathrm{N} 250^{\circ} \mathrm{E}$ direction. Also, the worldwide character of the present analysis allowed for a systematic search for singular events within the twentieth century secular variation. Seven such events have been detected, two being unquestionably of global extent (1969 and 1978), three being of possibly similar extent (1901, 1913, and 1925), while the remaining two are not seen everywhere at the Earth's surface (1932 and 1949).

The two 1969 and 1978 global events display an intriguing spatio-temporal behavior consisting of an early arrival in the northern hemisphere followed by a later arrival in the southern hemisphere. In addition, these two events tend to balance each other, as already noted by Stewart [1991] and Le Huy [1995] on the basis of an entirely different analysis.

The two-step behavior of these two events also accounts for the observations made by previous authors for "late" jerks in the southern hemisphere (Gubbins and Tomlunson [1986] and Whaler [1987] for a 1971/1972
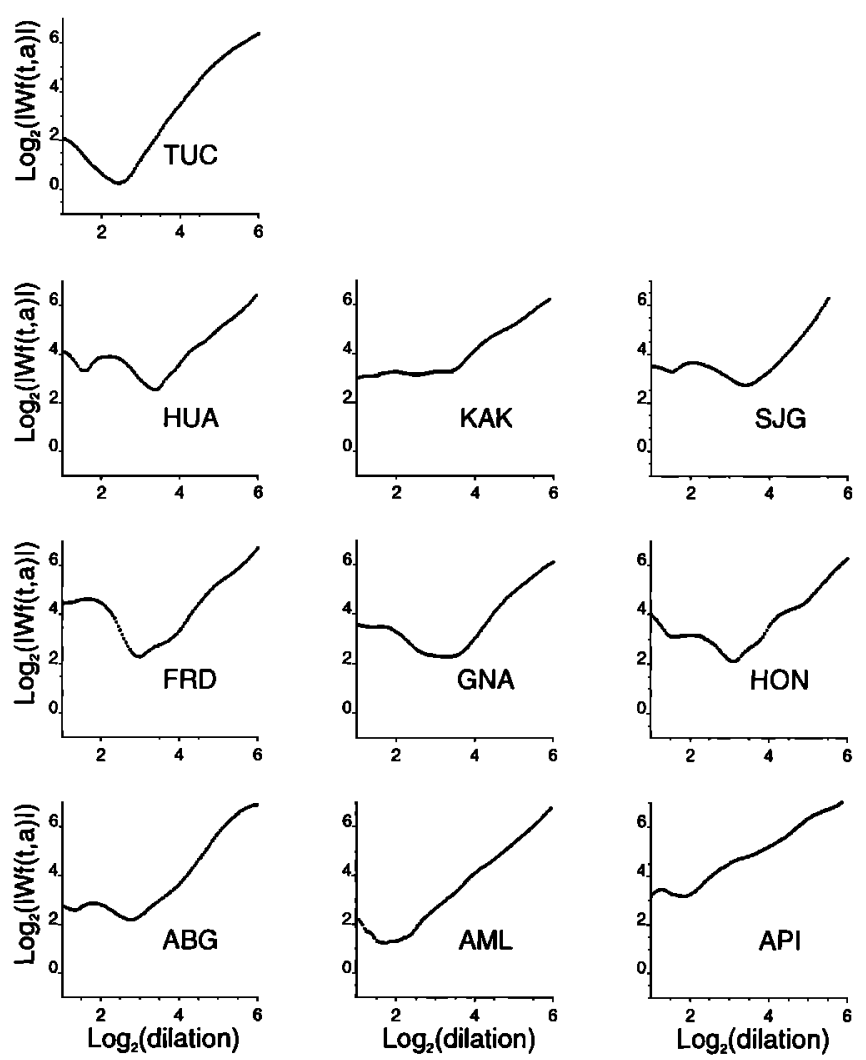

Figure 9. Log-log plots of the ridge functions of the 1949 event (see Table 2a for the code and location of the observatories and Table 3e for ridge function slopes). 

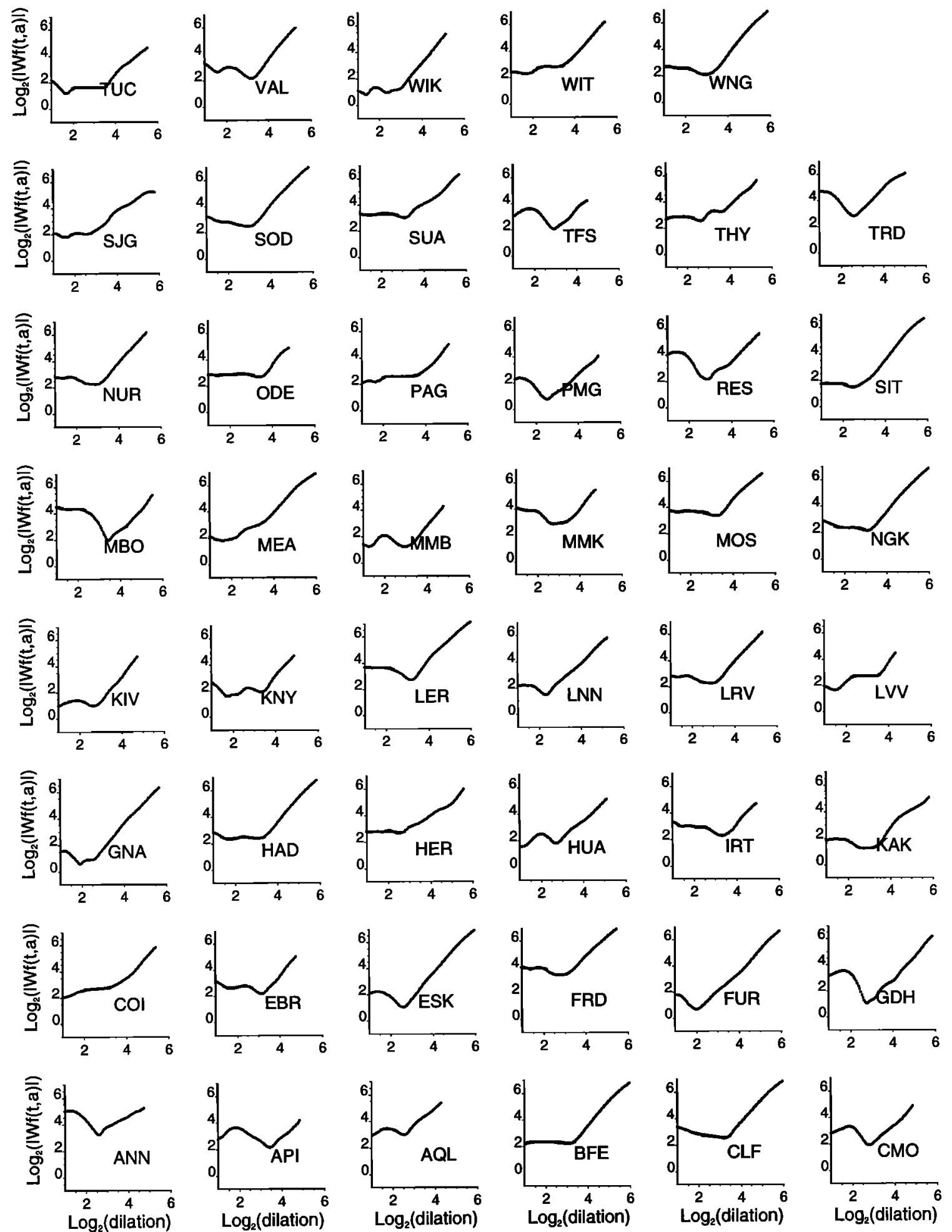

Figure 10. Log-log plots of the ridge functions of the 1969 event (see Table 2a for the code and location of the observatories and Table $3 \mathrm{f}$ for ridge function slopes).

jerk and Dowson et al. [1988], Kotzé et al. [1991], and Stewart [1991] for a 1983 jerk).

Turning now to the regularities, we confirm our early result that they are closer to 1.5 than to 2 . We can furthermore state that this is true for all events, with an overall common value of about $\alpha \approx 1.6$, and for the much better documented 1969 and 1978 events, the regularity seems to be slightly larger for the early northern arrival than for the late southern arrival. This could reflect some general property of the evolution of the flow 

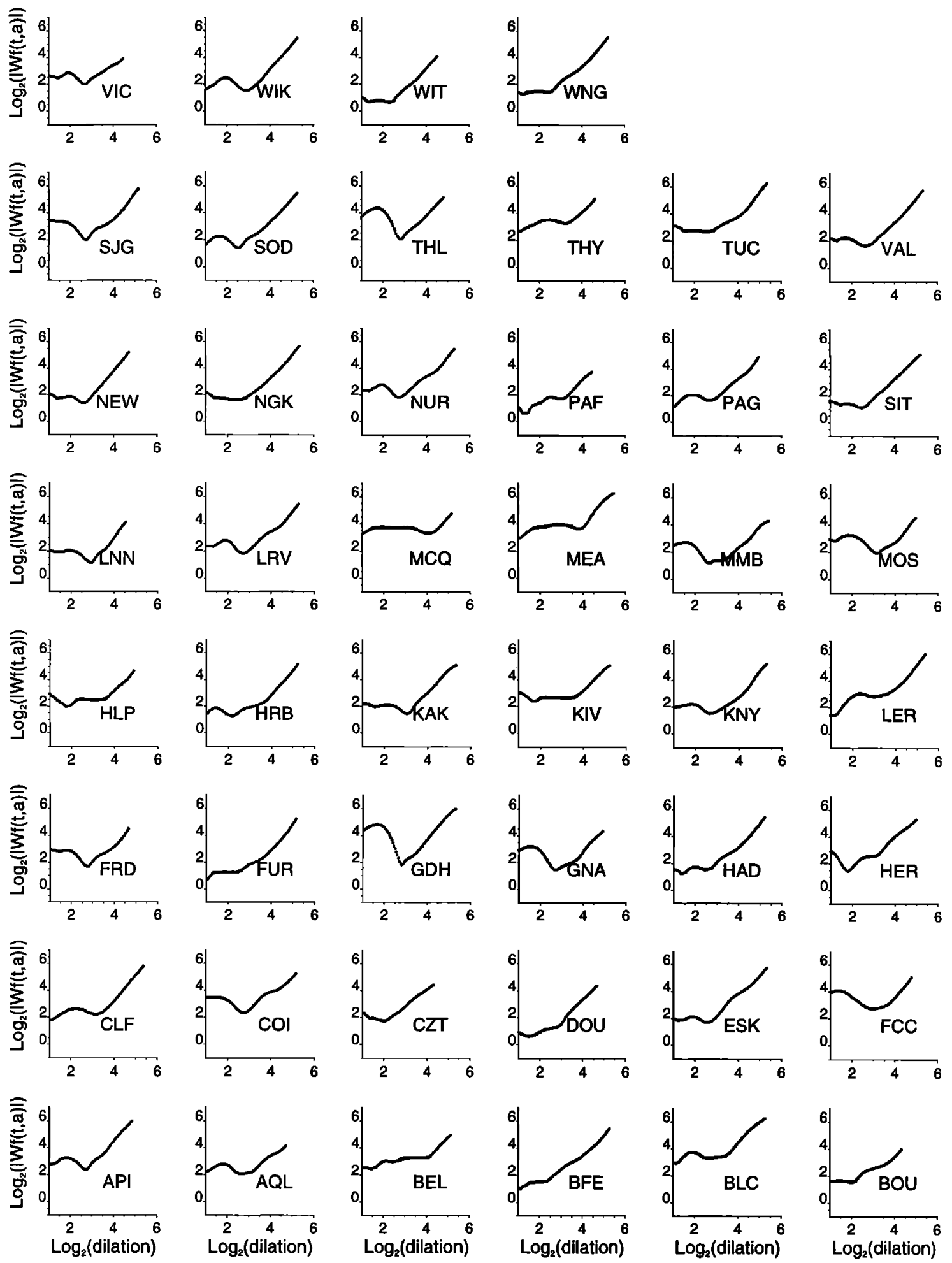

Figure 11. Log-log plots of the ridge functions of the 1978 event (see Table 2a for the code and location of the observatories and Table $3 \mathrm{~g}$ for ridge function slopes).

at the top of the core. However, this regularity is not so straightforward to interpret. As already pointed out, our analysis relies on the assumption that the jerks be linearly polarized in the horizontal plane. This is not necessarily the case since the geometry of the secular variation is not constant in time at the Earth's sur- face. This means that what we actually measure could be some kind of combination of two different singularities corresponding to two perpendicular horizontal components. Nevertheless, the fact that we were able to find a direction for which the signal is actually extinguished, and that, perpendicularly to this direction, we 


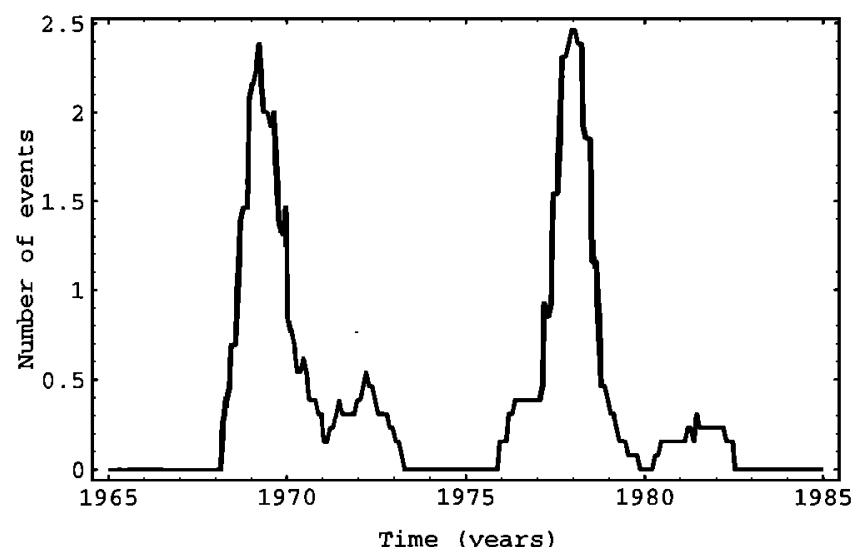

Figure 12. Histogram of the dates of the 1969 and 1978 jerks. obtained in most cases a reasonably linear behavior of the ridge functions within the range of dilations of interest, validates a posteriori our analysis. Let us recall that the main aim of the present paper was to carefully screen the twentieth century magnetic data for all possible events, to best characterize their temporal behavior, and to sketch their global geometry. A more detailed study of each event, especially with respect to the intensity $\beta$ of the signal, remains to be done. We again underline the fact that more data could also be recovered to complete our study. Indeed, whereas the number of observatories in operation at the beginning of the century was limited for obvious reasons, it is still disappointingly small for the 1978 event. This stresses the need for an implemented array of magnetic obser-

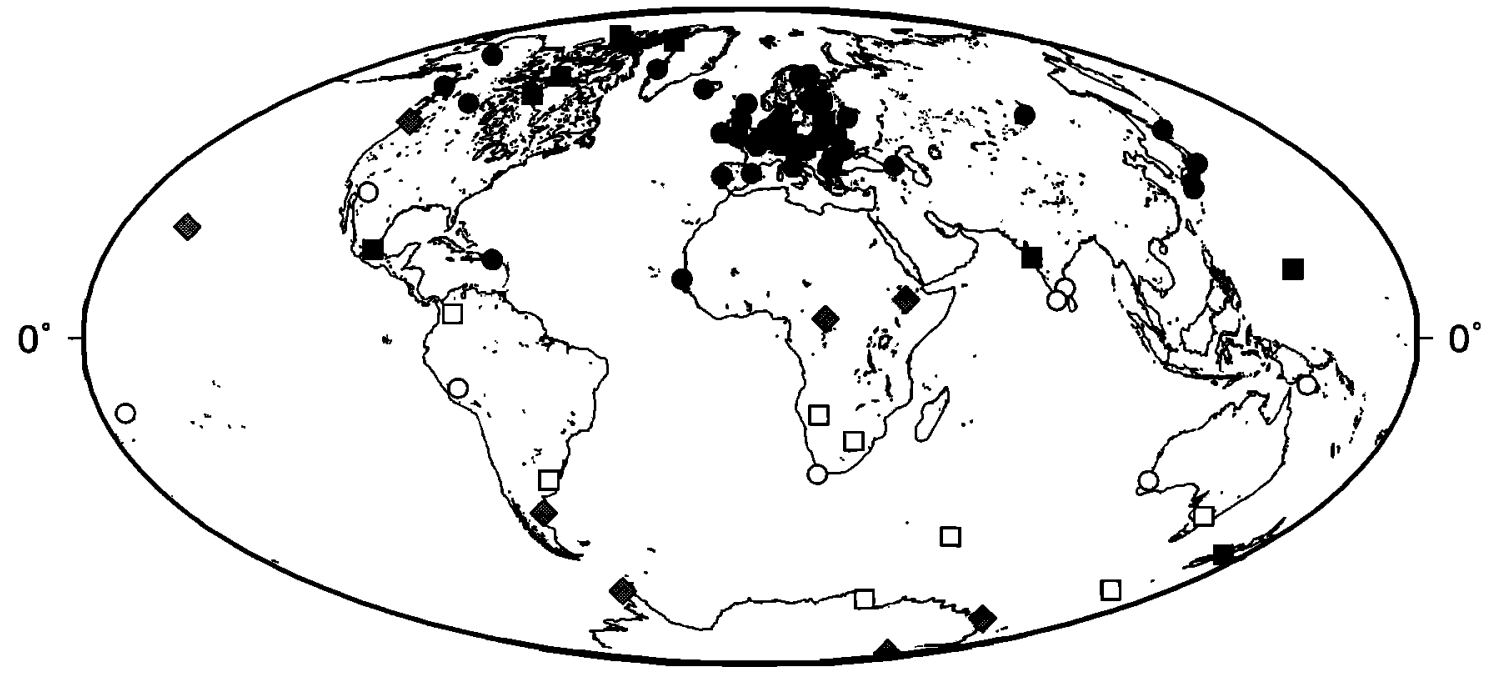

Figure 13. Times of occurrence of the 1969 event. These are detected using either the wavelet transform maps (before 1971, solid squares; after 1971, open squares) or the ridge functions (before 1971, solid circles; after 1971, open circles; see also Table $3 \mathrm{f}$ for more details). In some observatories the jerk is not detected (gray diamond).

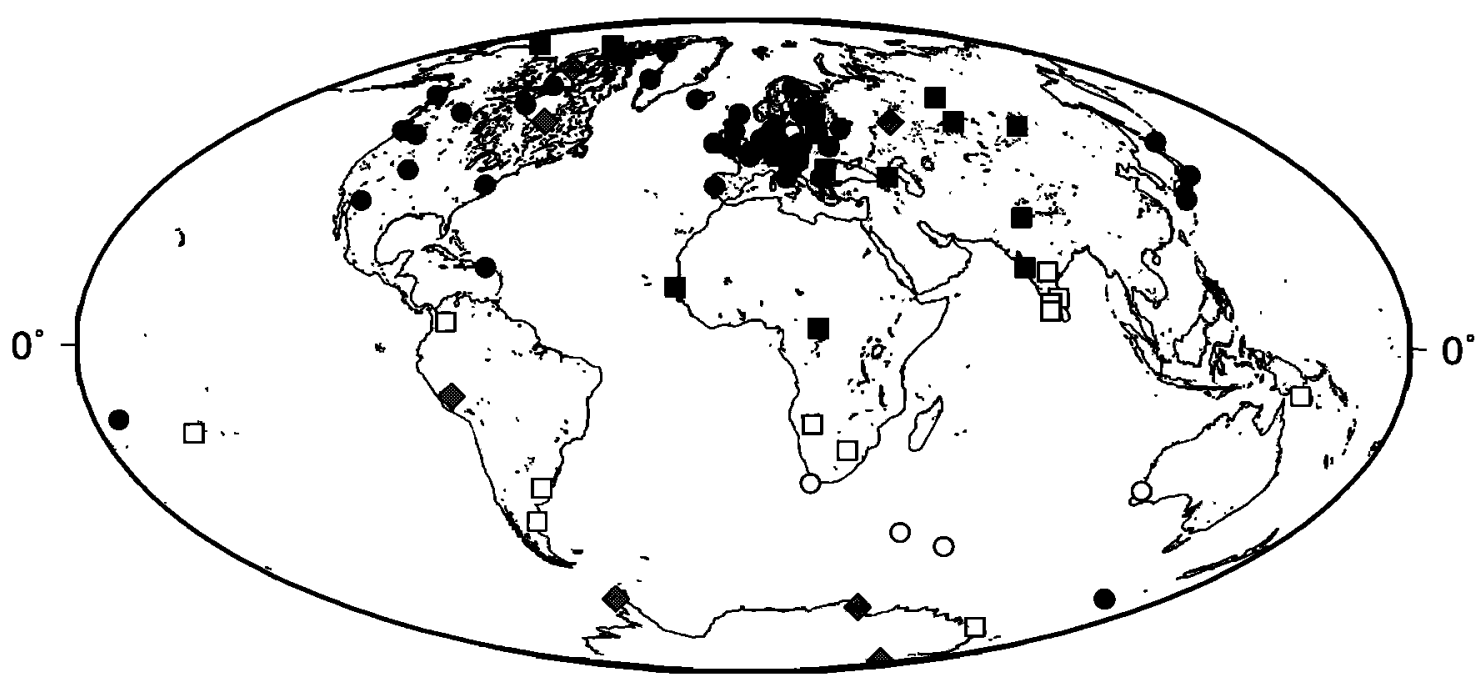

Figure 14. Times of occurrence of the 1978 event. These are detected using either the wavelet transform maps (before 1980, solid squares; after 1980, open squares) or the ridge functions (before 1980, solid circles; after 1980 open circles; see also Table $3 \mathrm{~g}$ for more details). In some observatories the jerk is not detected (gray diamond). 


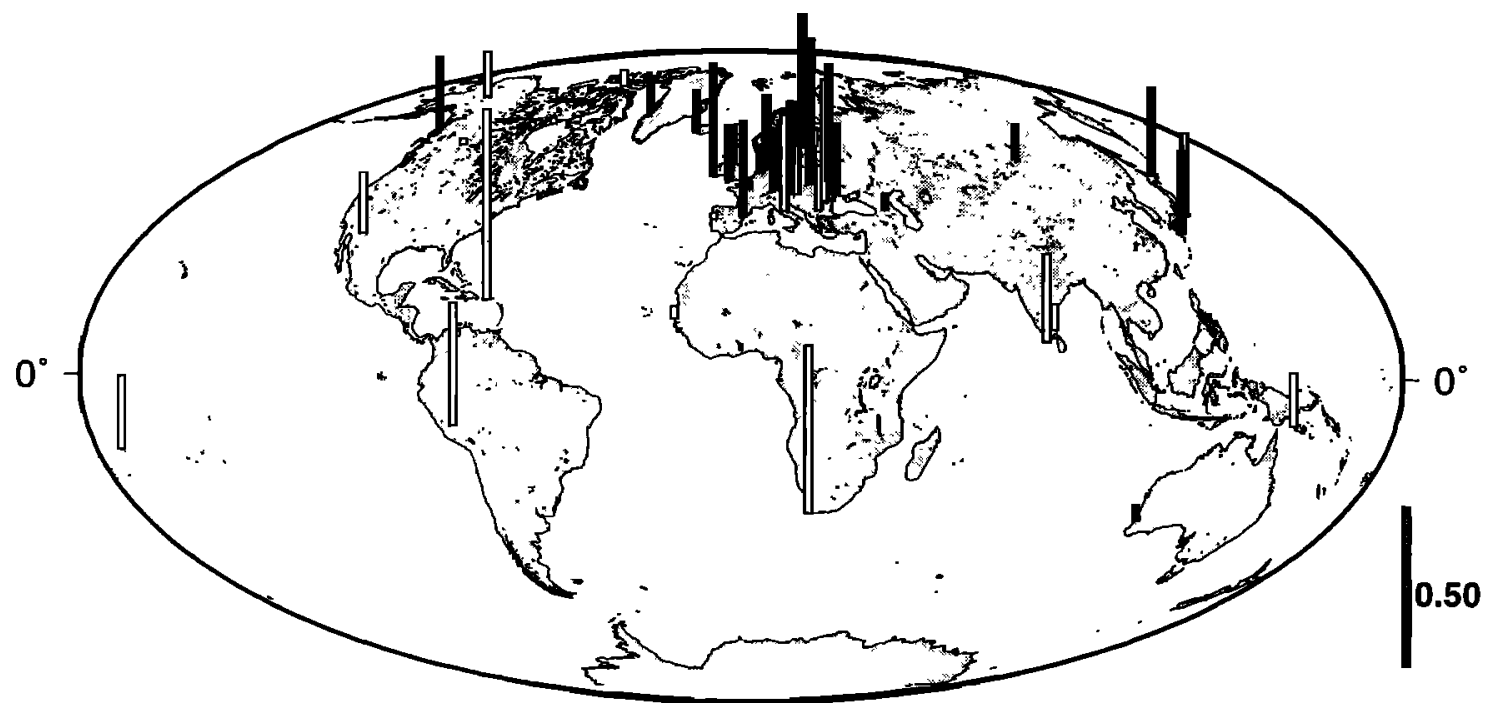

Figure 15. Departures of the regularities from the average value for the 1969 jerk. The black bars indicate positive values, and the white ones indicate negative values.

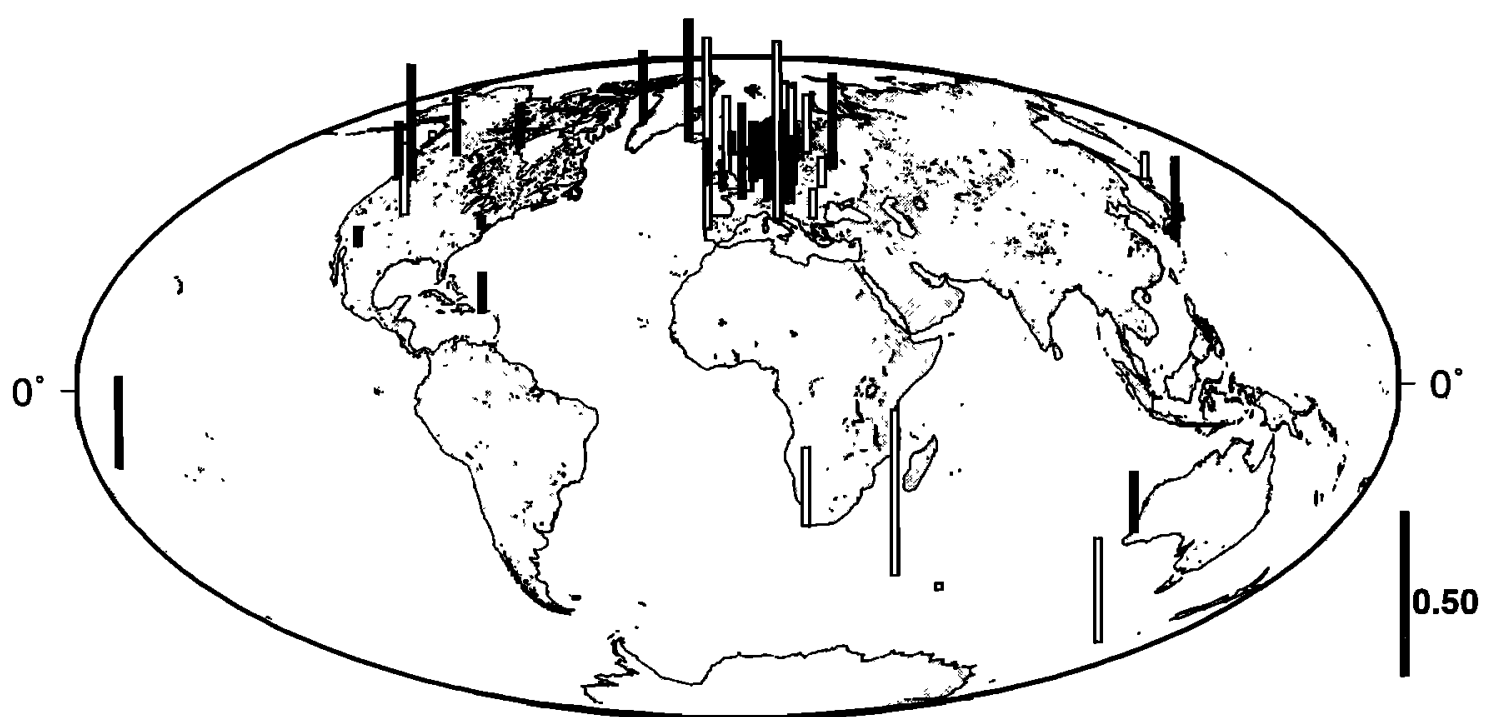

Figure 16. Departures of the regularities from the average value for the 1978 jerk. The black bars indicate positive values, and the white ones indicate negative values.

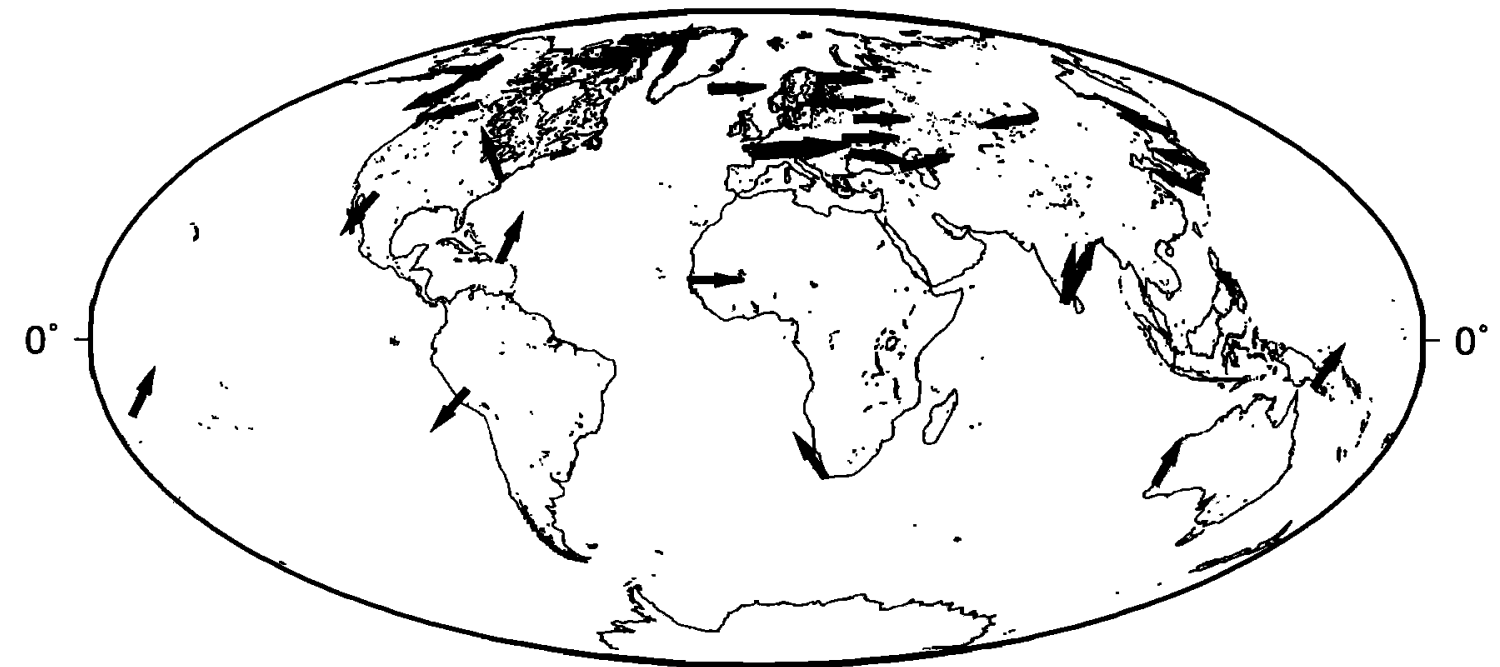

Figure 17. Characteristic directions and senses of the 1969 jerk. The longest arrow indicates the average direction and sense for the European observatories (see also Table $3 \mathrm{f}$ for more details). 


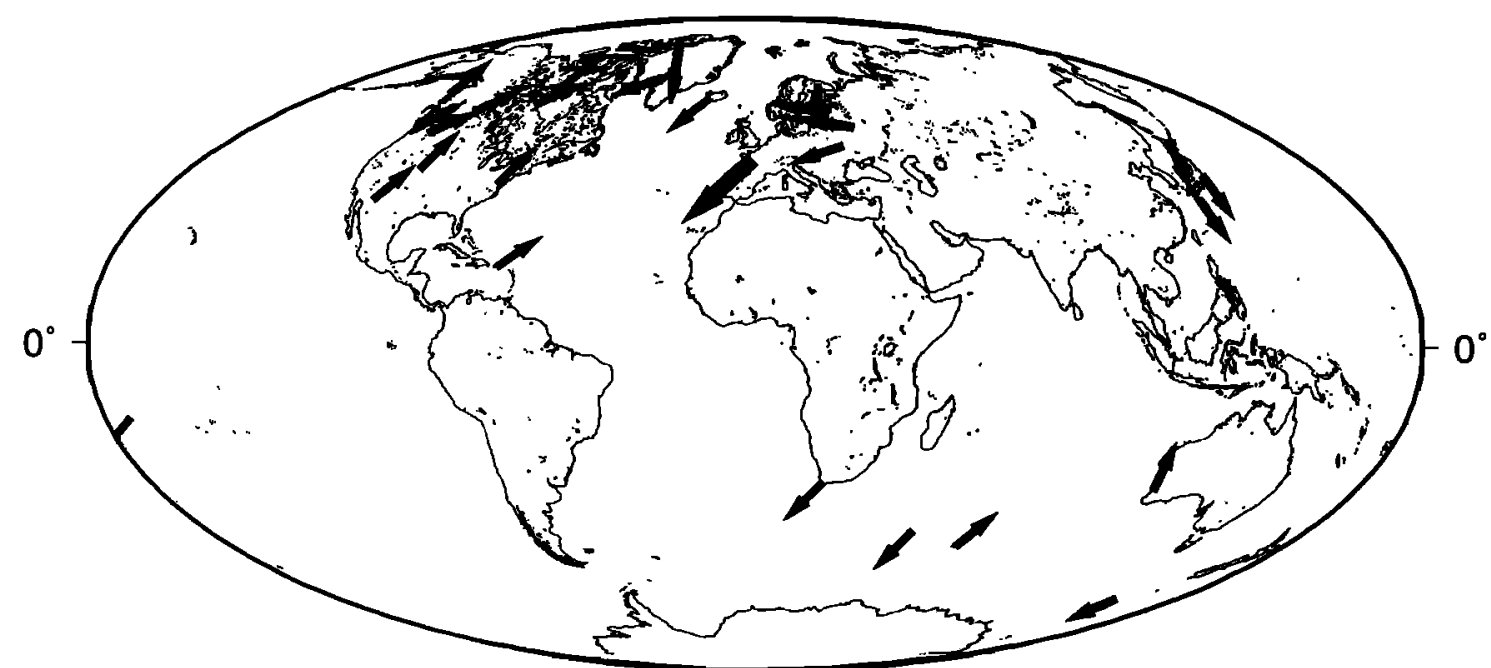

Figure 18. Characteristic directions and senses of the 1978 jerk. The longest arrow indicates the average direction and sense for the European observatories (see also Table $3 \mathrm{~g}$ for more details).

vatories making their data rapidly available (as in the Intermagnet program).

Finally, let us note that it is now time to try to understand the mechanism of these events: they have a large, sometimes global, extension at the surface of the Earth; they occur simultaneously, within the analysis accuracy, at places tens of thousands of kilometers apart, but can also be observed in one hemisphere a few years before the other one (this might have something to do with

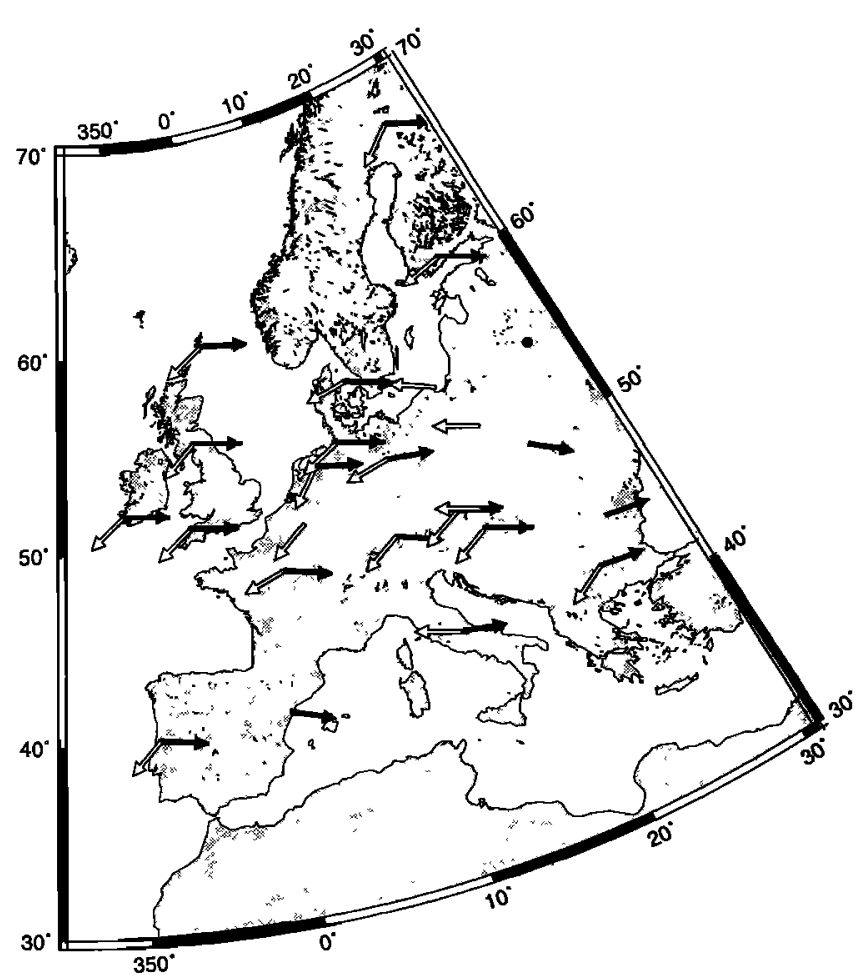

Figure 19. The directions and senses of the 1969 (black arrows) and 1978 (white arrows) jerks for the European observatories (see also Tables $3 \mathrm{f}$ and $3 \mathrm{~g}$ for more details). the delays introduced by the conductivity of the mantle [Backus, 1983]); they govern the secular variation for years or decades after they have occurred, as shown also by the observation that they are caused by sudden changes in the evolution of the flow at the top of the core [Hulot et al., 1993]. Any further progress concerning the origin of the secular variation will require that we simultaneously address the origin of the geomagnetic jerks.

\section{Appendix: Wavelet Transform}

In order to make this paper self-consistent, we recall the main aspects of the wavelet analysis method used in the present study. A more detailed discussion about both the mathematical aspects and the numerical assessment of the method is given in paper 1 [Alexandrescu et al., 1995]. Only those aspects of the wavelet transform directly relevant to this paper are presented, and the reader interested in the wavelet transform from a more general point of view is referred to Meyer [1990], Daubechies [1992], and Holschneider [1995]. Works on singularity detection with wavelets are given by Grossmann [1986], Grossmann et al. [1987], and Mallat and Hwang [1992].

We define the continuous wavelet transform of a signal $f(t)$ by the convolution product

$$
W f[t, a] \equiv\left[f * \psi_{a}\right](t),
$$

where the wavelets $\psi_{a}(t)$ are obtained by dilating an analyzing wavelet $\psi(t)$,

$$
\psi_{a}(t) \equiv \frac{1}{a} \psi\left(\frac{t}{a}\right)
$$

with a dilation $a>0$. Equation (A1) shows that the wavelet transform is defined in the $(t, a)$ open half-space and that every voice $W f(t, a=c s t)$ is a filtered version 
of the initial signal $s(t)$. The fact that the wavelet family $\psi_{a}(t)$ is generated through dilations of an analyzing wavelet $\psi(t)$ being well localized along the time axis makes the wavelet transform a useful tool to analyze the signal $f(t)$ at any timescale and reveal its possible self-similar behavior. In the present study we use the same analyzing wavelet as in paper 1 ,

$$
\psi(t)=\frac{d^{3}}{d t^{3}} \exp \left(-\frac{t^{2}}{2}\right)
$$

Consider now the particular case of a horizontal component of the geomagnetic field, assumed to be of the form

$$
f(t)=\beta j_{\alpha}(t)+h(t)+n(t),
$$

where the jerk is given by

$$
j_{\alpha}(t)=\left\{\begin{array}{ll}
0 & t \leq t_{0} \\
\left(t-t_{0}\right)^{\alpha} & t \geq t_{0}
\end{array} .\right.
$$

Variable $h(t)$ is a harmonic component of the form

$$
h(t)=\sum_{i} \gamma_{i} \sin \left(\frac{2 \pi t}{T_{i}}+\varphi_{i}\right),
$$

where $\gamma_{i}$ and $\varphi_{i}$ are amplitude and phase terms respectively, and $T_{i}$ are the main Fourier periods of the external field (i.e., $1 / 2,1,11 / 3,11 / 2$, and 11 years). The term $n(t)$ is assumed to be Gaussian-white noise with a zero mean and a variance $\sigma_{n}^{2}$. Inserting model (A4) into (A1) we obtain

$$
W f(t, a)=\beta W j_{\alpha}(t, a)+W h(t, a)+W n(t, a),
$$

which indicates that the wavelet transform of the signal is the superposition of the wavelet transforms of the jerk, of the harmonic components, and of the noise. The task is now to examine under which conditions a possible term $W j_{\alpha}$ may be identified in the whole wavelet transform $W f$, and how both the regularity $\alpha$ and the date $t_{0}$ of the jerk can be recovered.

According to paper 1 , and setting $t_{0}=0$,

$$
W j_{\alpha}(t, a)=\Gamma(\alpha+1) a^{\alpha} \psi^{-(\alpha+1)}\left(\frac{t}{a}\right)
$$

where the notation $\psi^{-(\cdot)}$ is for the fractional primitive:

$$
\frac{d^{\alpha+1}}{d t^{\alpha+1}} \psi^{-(\alpha+1)} \equiv \psi
$$

Using (A8), we obtain

$$
W j_{\alpha}(t, a)=\left(\frac{a}{a^{\prime}}\right)^{\alpha} W j_{\alpha}\left(t \frac{a^{\prime}}{a}, a^{\prime}\right),
$$

which indicates that the wavelet transform $W j_{\alpha}(t, a)$ can be recovered by dilating and scaling a single voice $W j_{\alpha}\left(t, a^{\prime}\right)$. As a consequence, the wavelet transform of a jerk has a conelike pattern pointing toward the date of the jerk (Figure 20). This property implies that the existence of conelike energy patches in the experimental wavelet transform will indicate that jerks are present in the signal $f(t)$. Clearly, a change of the sign of the jerk $(\beta)$ will result in a change of a sign in the wavelet transform. This is represented by color or gray scale in the wavelet map (typically red or light gray for positive and blue or dark gray for negative). By comparison with the synthetic test, we can tell whether the jerk is positive $(\beta>0)$ or negative $(\beta<0)$.

Also the focusing of the cone toward the date $t_{0}$ when $a$ tends toward 0 makes it possible to date the occurrence of the jerk. The scaling $\left(a / a^{\prime}\right)^{\alpha}$ between two voices of the wavelet transform depends on the regularity $\alpha$ of the jerk which, in practice, is estimated by studying the variation of the wavelet coefficients taken along the lines of extrema of the wavelet transform where the signal-to-noise ratio is the highest (Figure 20). The set of absolute values of the wavelet coefficients belonging to a given line of extrema and ranked with respect to the dilation $a$ defines what will be referred to as a ridge function $r(a)$. When plotted in a log-log diagram, the ridge function are straight lines whose slopes equal the regularity $\alpha$ (Figure 21).
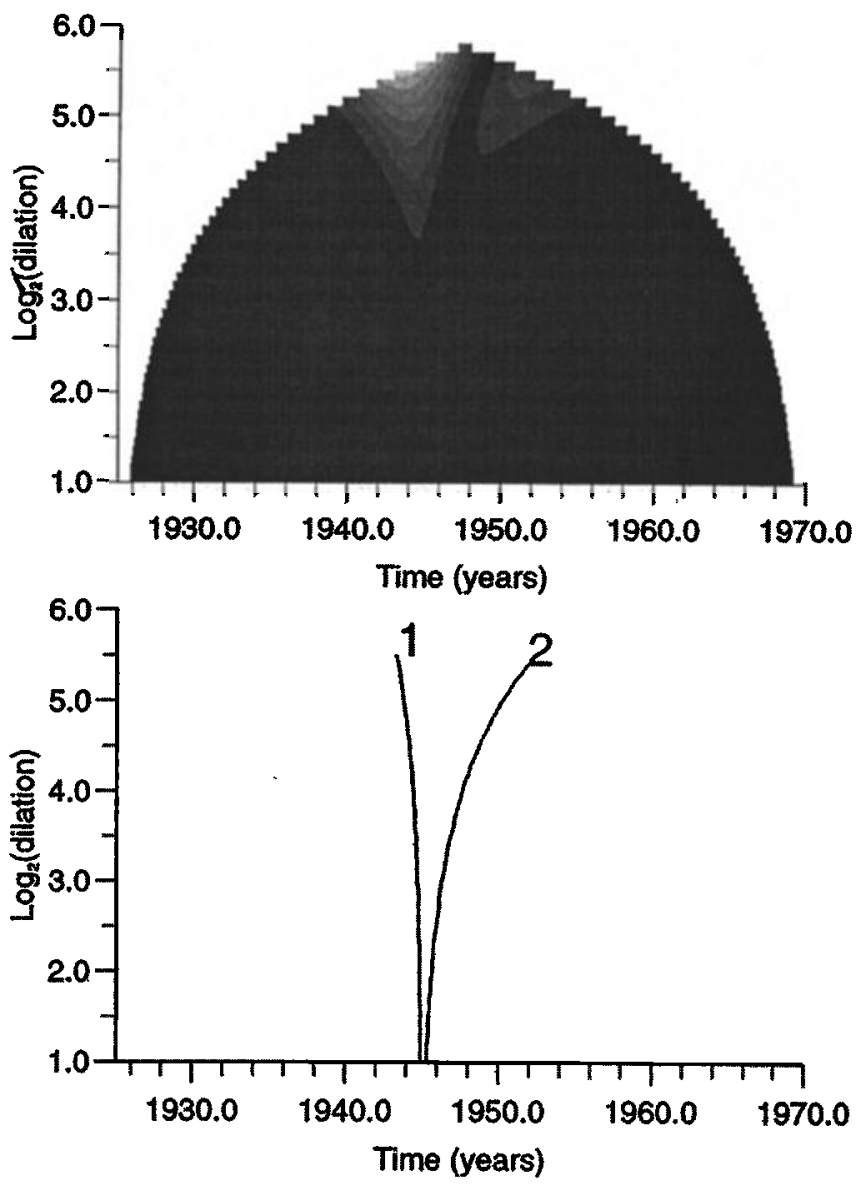

Figure 20. (top) Wavelet transform of a jerk with $\alpha=$ $1.6, \beta=0.17 \mathrm{nT} \times$ month $^{-1.6}$, and $t_{0}=1945$. Note the conelike structure of the wavelet map pointing toward the date of the jerk. The gray scale represents the sign of the wavelet transform: light gray indicates positive, dark gray indicates negative. (bottom) Lines of extrema extracted from the wavelet map of the jerk. These lines converge toward the date of the jerk. 

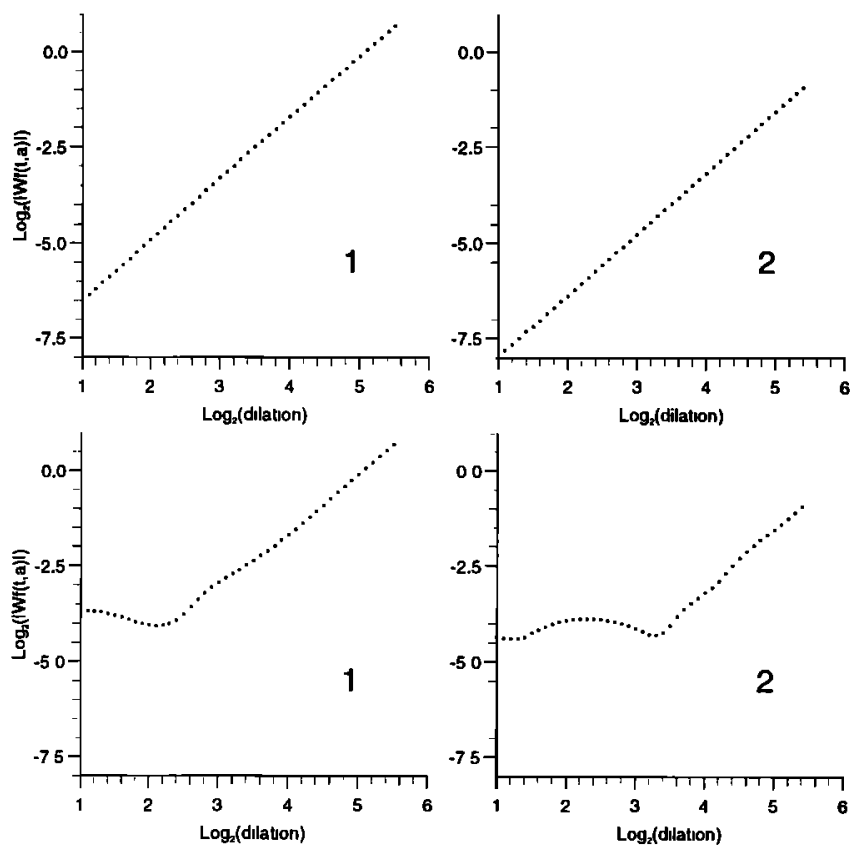

Figure 21. (top) Log-log plots of the ridge functions corresponding to the lines of extrema of Figure 21. The slopes of the ridge functions equal the regularity (here $\alpha=1.6$ ) of the jerk. (bottom) Ridge functions corresponding to the same jerk polluted with a Gaussian-white noise with zero mean and variance $\sigma_{n}^{2}=6 \times 10^{-4}$. The ridge functions are no more linear in a small-dilation range $a \leq a_{c} \simeq 2^{3.5}$ but remain so for $a>a_{c}$. The slopes of the linear parts of the ridge functions 1 and 2 are $\alpha=1.54$ and $\alpha=1.62$, respectively. Such ridge functions are considered to be of type 1.

The experimental wavelet transforms also contain the effects of both the noise and the harmonic components (equation (A7)). The effect of the noise is essentially limited to a small-dilation range $a \leq a_{c}$ for which the ridge functions cease to be linear (Figure 21). The value of $a_{c}$ depends on the relative strengths of both the jerks and the noise present in the data. In the present study as well as in paper 1 , when processing real data we found experimentally that $a_{c} \simeq 2^{35}$. The effects of the harmonic components are more complicated and not restricted to such a small-dilation range. Again, due to the linearity of the wavelet transform, we have

$$
W h(t, a)=\sum_{i} \gamma_{i} W\left[\sin \left(\frac{2 \pi t}{T_{i}}+\varphi_{i}\right)\right](t, a),
$$

where the transform of a single harmonic component reads

$$
\begin{gathered}
W\left[\sin \left(\frac{2 \pi t}{T_{i}}+\varphi_{i}\right)\right](t, a)= \\
(2 \pi)^{7 / 2}\left(\frac{a}{T_{i}}\right)^{3} \exp \left(-\frac{2 \pi^{2} a^{2}}{T_{i}^{2}}\right) \cos \left(\frac{2 \pi t}{T_{i}}+\varphi_{i}\right)
\end{gathered}
$$

This wavelet transform is extremum for

$$
a_{i}=T_{i} \sqrt{3} / 2 \pi
$$

along any line $t=$ const in the $(t, a)$ half plane. In general, the wavelet transform of the harmonic signal will possess numerous lines of extrema resulting from complicated interference between the transforms of the individual harmonic components. Although very variable in details, all ridge functions due to the harmonic signal share a common wobbling aspect (Figure 22) and an exponential decrease beyond the dilation

$$
a_{\max }=T_{\max } \sqrt{3} / 2 \pi,
$$

where $T_{\max }$ is the largest period present in the sum of (A6). For instance, if $T_{\max }=11$ years, then $a_{\max }=$ $2^{52}$. This sharp decrease characterizes the ridge functions of the harmonic signal whose behavior is then very different from those of jerks (Figure 22). This provides us with a means of classifying the ridge functions extracted from an experimental wavelet transform (paper 1):

Type 1 ridge functions are linear for large dilations, with a positive slope. They are possibly altered in a small-dilation range $a \leq a_{c}$ because of the presence of noise. Such type 1 ridge functions may safely be considered as mainly due to jerks.

Type 2 ridge functions have a wobbling appearance and display a sharp decrease for large dilation. This type of ridge functions will be principally due to the harmonic component.

Type 3 ridge functions are those not falling into either type 1 or type 2 and generally correspond to ridge functions caused by complicated interferences between the different terms of the experimental wavelet trans-
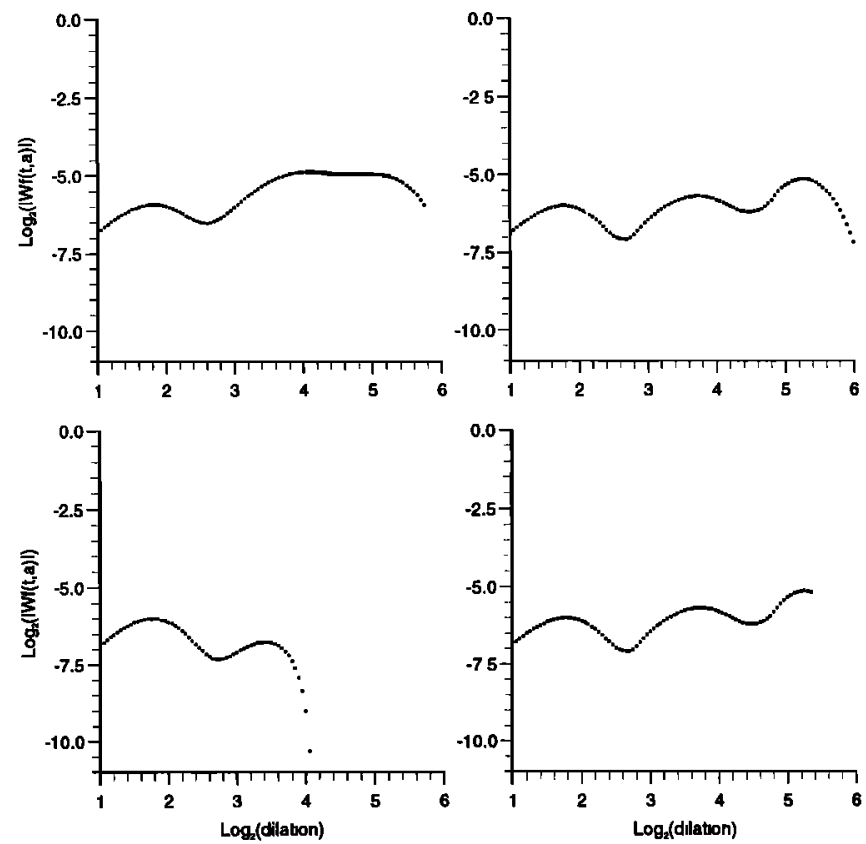

Figure 22. Typical ridge functions extracted from the wavelet maps of pure harmonic components $h(t)$ (equation (A11)) with the longest period $T_{\max }=11$ years. Note the wobbling aspect of these ridge functions and the sharp decrease beyond $a_{\max }=2^{5.2}$. Such ridge functions are considered to be of type 2 . 
form (equation (A7)). Such ridge functions cannot be given a clear origin.

Acknowledgments. We are pleased to thank the staff of the geomagnetic observatories for their kind supplying of high-quality data. Associate Editor Andrew Jackson, Susan Macmillan, and another anonymous referee made very constructive remarks. This is IPGP contribution 1428.

\section{References}

Achache, J., V. Courtillot, J. Ducruix, and J.-L. Le Mouël, The late 1960's secular variation impulse: Further constraints on deep mantle conductivity, Phys. Earth Planet. Inter., 23, 72-75, 1980.

Alexandrescu, M., D. Gibert, G. Hulot, J.-L. Le Mouël, and G. Saracco, Detection of geomagnetic jerks using wavelet analysis, J. Geophys. Res., 100, 12557-12572, 1995.

Alldredge, L.R., A discussion of impulses and jerks in the geomagnetic field, J. Geophys. Res., 89, 4403-4412, 1984.

Backus, G.E., Application of mantle filter theory to the magnetic jerk of 1969, Geophys. J. R. Astron. Soc., 74, 713746, 1983.

Courtillot, V., and J.-L. Le Mouël, Geomagnetic secular variation impulses: A review of observational evidence and geophysical consequences, Nature, $311,709-716,1984$.

Courtillot, V., and J.-L. Le Mouël, Time variations of the Earth's magnetic field: From daily to secular, Annu. Rev. Earth Planet. Sci., 16, 389-476, 1988.

Courtillot, V., J. Ducruix, and J.-L. Le Mouël, Sur une accélération récente de la variation séculaire du champ magnétique terrestre, C. R. Acad. Sci. Ser. D, 287, 1095-1098, 1978.

Currie, R.G., Magnetic shielding properties of the Earth's mantle, J. Geophys. Res., 72, 2623-2633, 1967.

Currie, R.G., Geomagnetic spectrum of internal origin and lower mantle conductivity, J. Geophys. Res., 73, 27792786, 1968.

Daubechies, I., Ten Lectures on Wavelets, CBMS Ser. Appl. Math., vol. 61, Soc. for Ind. and Appl. Math., Philadelphia, Pa., 1992.

Dowson, M.J., J.P. Buckingham, and D.A. Simmons, Notes on geomagnetic repeat measurements at Grytviken, April 1987, Br. Antarct. Surv. Bull., 71, 49-52, 1988.

Ducruix, J., and J.-L. Le Mouël, Existence et caractère planétaire d'une secousse de la variation séculaire du champ géomagnétique en 1912-1913, C. R. Acad. Sci. Ser. B, 296, 1419-1424, 1983.

Ducruix, J., V. Courtillot, and J.-L. Le Mouel, The late 1960's secular variation impulse, the eleven year magnetic variation and the electrical conductivity of the deep mantle, Geophys. J. R. Astron. Soc., 61, 73-94, 1980.

Gavoret, J., D. Gibert, M. Menvielle, and J.-L. Le Mouël, Long-term variations of the external and internal components of the Earth's magnetic field, J. Geophys. Res., 91, 4787-4796, 1986.

Gire, C., J.-L. Le Mouël, and J. Ducruix, Evolution of the secular variation field from the beginning of the century, Nature, 307, 349-352, 1984.

Golovkov, V.P., T.I. Zvereva, and A.O. Simonyan, Common features and differences between "jerks" of 1947, 1958 and 1969, Geophys. Astrophys. Fluid Dyn., 49, 81-96, 1989.

Grossmann, A., Wavelet transform and edge detection, in Stochastic Processes in Physics and Engineering, edited by M. Hazewinkel, pp. 149-157, D. Reidel, Norwell, Mass., 1986.

Grossmann, A., M. Holschneider, R. Kronland-Martinet, and J. Morlet, Detection of abrupt changes in sound signals with the help of wavelet transforms, in Inverse Problems: An Interdisciplinary Study; Adv. Electr. Electr. Phys., vol. 19, pp. 298-306, Academic, San Diego, Calif., 1987.

Gubbins, D., and L. Tomlinson, Secular variation from monthly means from Apia and Amberley magnetic observatories, Geophys. J. R. Astron. Soc., 86, 603-616, 1986.

Holschneider, M., Wavelet: An analysis tool, in Oxford Mathematical Monographs., Oxford U.P., New York, 423 pp., 1995.

Hulot, G., M. Le Huy, and J.-L. Le Mouël, Secousses (jerks) de la variation séculaire et mouvements dans le noyau terrestre, C. R. Acad. Sci. Ser. II, 317, 333-341, 1993.

Kotzé, P.B., G.J. Kühn, and G.L.M. Scheepers, Abrupt secular variation change in the southern African region in 1984, paper presented at XX General Assembly, Int. Union of Geod. and Geophys., Vienna, 1991.

Langel, R.A., D.J. Kerridge, D.R. Barraclough, and S.R.C. Malin, Geomagnetic temporal change: 1903-1982, a spline representation, J. Geomagn. Geoelectr., 38, 573-597, 1986.

Le Huy, M., Le champ géomagnétique, les mouvements du fluide à la surface du noyau et les variations décennales de la rotation de la Terre, $\mathrm{Ph}$. $\mathrm{D}$. thesis, 274 pp., Inst. de Phys. du Globe, Paris, 1995.

Malin, S.R., and B.M. Hodder, Was the 1970 geomagnetic jerk of internal or external origin?, Nature, 296, 726-728, 1982.

Malin, S.R.C., B.M. Hodder, D.R. Barraclough, Geomagnetic secular variation: A jerk in 1970, in 75th Anniversary Volume of Ebro Observatory, edited by J.O. Cardus, 239-256, Roquetes, Tarragona, Spain, 1983.

Mallat, S., and W.L. Hwang, Singularity detection and processing with wavelets, IEEE Trans. Inf. Theory, 38, 617643, 1992.

McLeod, M.G., On the geomagnetic jerk of 1969, J. Geophys. Res., 90, 4597-4610, 1985.

McLeod, M.G., Geomagnetic secular variation, in Geomagnetism and Paleomagnetism, edited by F.J. Lowes, D.W. Collison, J.H. Parry, S.K. Runcorn, D.C. Tozer and A. Soward, Kluwer Acad., Boston, Mass., 19-30, 1989.

Meyer, Y., Ondelettes et opérateurs, 383 pp., Hermann, Paris, 1990.

Scales, J., Theory of seismic imaging, Lecture Notes in Earth Sciences, vol. 55, 291 pp., Springer-Verlag, New York, 1995.

Stewart, D.N., Geomagnetic impulses and the electrical conductivity of the lower mantle, Ph. D. thesis, Dep. of Earth Sci., Univ. of Leeds, Leeds, England, 1991.

Stewart, D.N., and K.A. Whaler, Optimal piecewise regression analysis and its application to geomagnetic time-series, Geophys. J. Int., 121, 710-724, 1995.

Whaler, K.A., A new method for analysing geomagnetic impulses, Phys. Earth Planet. Inter., 48, 221-240, 1987.

M. Alexandrescu, G. Hulot, and J.-L. Le Mouël, Institut de Physique du Globe, B.P. 89, 4 Place Jussieu, 75252 Paris cedex 5, France. (e.mail: mioara@ipgp.jussieu.fr; ghulot@ipgp.jussieu.fr; lemouel@ipgp.jussieu.fr)

D. Gibert, and G. Saracco, Géosciences Rennes, Université de Rennes 1, Bât. 15 Campus de Beaulieu, 35042 Rennes cedex, France. (e.mail: gibert@univ-rennes1.fr; ginet@univ-rennes1.fr)

(Received December 28, 1995; revised May 9, 1996; accepted May 17, 1996.) 